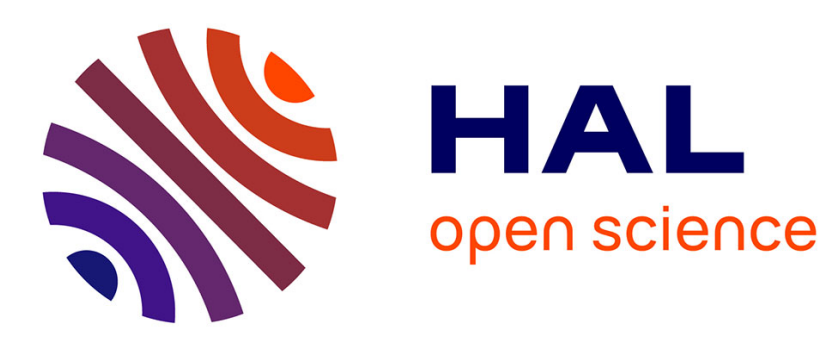

\title{
Numerical Analysis of Junctions between Thin Shells, Part 2: Approximation by Finite Element Methods
}

\author{
Michel Bernadou, Annie Cubier
}

\section{To cite this version:}

Michel Bernadou, Annie Cubier. Numerical Analysis of Junctions between Thin Shells, Part 2: Approximation by Finite Element Methods. [Research Report] RR-2922, INRIA. 1996. inria-00073776

\section{HAL Id: inria-00073776 \\ https://hal.inria.fr/inria-00073776}

Submitted on 24 May 2006

HAL is a multi-disciplinary open access archive for the deposit and dissemination of scientific research documents, whether they are published or not. The documents may come from teaching and research institutions in France or abroad, or from public or private research centers.
L'archive ouverte pluridisciplinaire HAL, est destinée au dépôt et à la diffusion de documents scientifiques de niveau recherche, publiés ou non, émanant des établissements d'enseignement et de recherche français ou étrangers, des laboratoires publics ou privés. 
INSTITUT NATIONAL DE RECHERCHE EN INFORMATIQUE ET EN AUTOMATIQUE

\section{Numerical analysis of junctions between thin shells, Part 2 : Approximation by finite element methods}

Michel Bernadou, Annie Cubier

$\mathbf{N}^{\circ} \mathbf{2 9 2 2}$

Juin 1996

THÈME 4

apport

de recherche 

Numerical analysis of junctions between thin shells, Part 2 : Approximation by finite element methods

\author{
Michel Bernadou, Annie Cubier ${ }^{* *}$ \\ Thème 4 - Simulation \\ et optimisation \\ de systèmes complexes \\ Projet MODULEF
}

Rapport de recherche $\mathrm{n}^{\circ} 2922$ - Juin 1996 - 36 pages

\begin{abstract}
The purpose of this work is to study the numerical analysis of junctions between thin shells. We describe the approximation by a "pseudo-conforming" finite element method associated with the Argyris triangle and taking into account the numerical integration. Under suitable hypothesis on the integration schemes and on the data, we prove the convergence of this method and we derive a priori error estimates.
\end{abstract}

Key-words: Thin shells. Elastic junction. Rigid junction. Argyris Triangle. Numerical integration. Error estimate. Numerical simulations

Pôle Universitaire Léonard de Vinci

INRIA Rocquencourt 


\section{Analyse numérique de jonctions de coques minces, Partie 2 : Approximations par des méthodes d'éléments finis}

Résumé : Le but de cet article est l'analyse numérique du problème de jonctions de coques minces. Nous décrivons une méthode d'approximation "pseudoconforme" utilisant l'élément fini d'Argyris et prenant en compte les phénomènes liés à l'intégration numérique. Sous des hypothèses convenables sur les schémas d'intégration numériques et sur les données, nous montrons la convergence de cette méthode et nous donnons des estimations d'erreur a priori tant pour le problème de jonction élastique que pour le problème de jonction rigide.

Mots-clé : Coques minces. Jonction élastique. Jonction rigide. Triangle d'Argyris. Intégration numérique. Estimations d'erreur. Simulations numériques. 


\section{$1 \quad$ Introduction}

The numerical analysis of junctions between thin plates was studied by BernadouFayolle-Léné (1989) while Fayolle (1987) thoroughly described the corresponding approximation by conforming finite element methods. Such an approximation is much more complicated in case of junctions between two general thin shells. Indeed the transmission conditions which appear in the definition of the admissible spaces cannot be exactly satisfied in the associated discrete spaces. Thus, we consider pseudo-conforming finite element methods which are conforming everywhere except along the junction.

In the first part of this work (Bernadou-Cubier, to appear), we analyse the continuous problems of junctions between two thin shells associated with an elastic or a rigid behaviour of the hinge. We start by giving the equilibrium equations of these problems and the corresponding variational formulations. We study the numerical properties of theses equations and show the existence and uniqueness of the solution. We also prove that the solution of the elastic junction problem converges to the solution of the rigid junction problem when the coefficient of elastic stiffness of the hinge becomes very large.

In this second part of the work, we start in Section 2 by rewriting the continuous problems in terms of matrices and vectors, which are well adapted to the approximation by finite element methods. In Section 3, we build the discrete spaces which are associated with the Argyris triangle, and which contain the discrete junction conditions. The discretization of the transmission conditions is based on the results obtained by Zenisek (1981) for nonhomogeneous boundary conditions. From Section 4, we restrict our attention to the elastic junction problem ; we give the main results concerning the rigid junction problem in Section 6 . Then, we state the first discrete problem taking into account the finite element approximation and the nonconformity of the method along the hinge. We introduce in this problem an additional linear form which is void for continuous problem and which takes into account the nonconformity of the method. Then we prove the existence and uniqueness of the solution. This result is based on the transmission of a clamped condition by the discrete junction conditions described in Section 3. Afterwards, we give an abstract error estimate which is reduced to the usual interpolation error ; this is a direct consequence of the definition of the discrete problem by using an additional linear form as mentionned before. In Section 5, we study the second discrete problem which takes into account the additional effect of the numerical integration. We prove the uniform ellipticity of the bilinear forms and thus the existence and uniqueness of the solution of this problem. Next, we give criteria on the integration schemes and required regularity conditions on the data so that the finite element method converges. These conditions lead to asymptotic error estimates of the same order than the interpolation error. These results are based on local error estimates studied by Bernadou (1996) and Cubier (1994). In Section 7, we illustrate previous results by some numerical tests on rigid and elastic junctions between a cylinder and a spherical end cap. In order to validate our results, we consider a corresponding 
test using the three dimensional elasticity model instead of a shell model and which represents a good approximation of a rigid junction. The result of this test is very closed to ours obtained for rigid junction. Moreover, we find again numerically that the elastic junction becomes almost rigid when the coefficient of elastic stiffness of the hinge becomes very large.

Notations and references: In this second part, we make many references to the notations and to the results of Part 1, just by adding "Part 1" before each reference.

\section{Variational formulations in matrix form}

In this section, we give new expressions in terms of vectors and matrices for the bilinear and linear forms which appear in the variational formulations of the elastic and rigid junction problems (Part 1, (3.10) and (3.24)). The bilinear form $a[.,$. which represents the addition of the strain energy of both shells, can be written

$$
a[(\boldsymbol{u} ; \boldsymbol{u}),(\boldsymbol{v} ; \boldsymbol{v})]=\int_{\Omega}{ }^{T}[\boldsymbol{U}][\boldsymbol{A}][\boldsymbol{V}] d \xi^{1} d \xi^{2}+\int_{\Omega}{ }_{\Omega}^{T}[\boldsymbol{U}][\underset{\boldsymbol{A}}{\boldsymbol{A}}][\underset{\sim}{\boldsymbol{V}}] d \underset{\sim}{\xi^{1}} d{\underset{\sim}{2}}^{2}
$$

where the column matrix $[\boldsymbol{V}]$ (and similarly $[\boldsymbol{U}],[\boldsymbol{U}],[\boldsymbol{V}]$ ) is given by :

$$
{ }^{T}[\boldsymbol{V}]_{1 \times 12}=\left[\begin{array}{llllllllllll}
v_{1} & v_{1,1} & v_{1,2} & v_{2} & v_{2,1} & v_{2,2} & v_{3} & v_{3,1} & v_{3,2} & v_{3,11} & v_{3,12} & v_{3,22}
\end{array}\right],
$$

and where the symmetrical $12 \times 12$ matrix $[\boldsymbol{A}]$ (respectively $[\boldsymbol{A}]$ ) depends only on the shell thickness $e$, on the mechanical characteristics of the shell and on the first, second and third partial derivatives of the application $\Phi: \bar{\Omega} \rightarrow \overline{\mathcal{S}}$ (resp. $\Phi: \bar{\Omega} \rightarrow \overline{\mathcal{S}}$ ) which maps $\Omega$ (resp. $\Omega$ ) onto the middle surface $\mathcal{S}$ (resp. $\mathcal{S}$ ). Subsequently, we assume that $\Phi \in\left(C^{3}(\bar{\Omega})\right)^{3}$ and $\Phi \in\left(C^{3}(\underset{\Omega}{\Omega})\right)^{3}$.

The second bilinear form $b[.,$.$] which appears in the variational formulation of$ elastic junction between shells (Part 1, (3.10)) is associated with the strain energy of the hinge. We define a $24 \times 24$ matrix $[\boldsymbol{C}]$ which only depends on the geometry of the hinge, and a column vector $\left[\begin{array}{ll}\boldsymbol{V} & \boldsymbol{V}\end{array}\right]_{24 \times 1}$ which collects the vectors $[\boldsymbol{V}]$ and $[\boldsymbol{V}]$ defined by relation $(2.2)$. Thus, we have :

$$
\left.b[(\boldsymbol{u} ; \boldsymbol{u}),(\boldsymbol{v} ; \boldsymbol{v})]=\int_{\Gamma} T_{[} \boldsymbol{U} \quad \boldsymbol{U}\right][\boldsymbol{C}]\left[\begin{array}{ll}
\boldsymbol{V} & \boldsymbol{V}
\end{array}\right] d s .
$$

Moreover, we introduce a new parameterization of the hinge $\Gamma$, as the image of a one-dimensional interval $\omega=] 0,1[$ by a mapping $\underline{\Phi}$, i.e., $\underline{\Phi}: \bar{\omega} \rightarrow \bar{\Gamma}$. Now, we can substitute this application $\underline{\Phi}$ into relation (2.3) to obtain

$$
b[(\underline{\boldsymbol{u}} ; \underline{\underline{\boldsymbol{u}}}),(\underline{\boldsymbol{v}} ; \underline{\underline{\boldsymbol{v}}})]=\int_{\omega}{ }^{T}[\underline{\boldsymbol{U}} \underline{\boldsymbol{U}}][\underline{\boldsymbol{C}}][\underline{\boldsymbol{V}} \underline{\boldsymbol{V}}] d \omega,
$$

where the underlined quantities are obtained by composition with the mapping $\underline{\Phi}$ and are defined on the interval $\omega$. The element $d \omega$ is associated to the line element $d s$ along the hinge $\Gamma$ through the mapping $\underline{\Phi}=\sum_{i=1}^{3} \underline{\Phi}_{i}(t) \boldsymbol{e}_{i}$ :

$$
d s=\left[\left(d x_{1}\right)^{2}+\left(d x_{2}\right)^{2}+\left(d x_{3}\right)^{2}\right]^{1 / 2},
$$


so that

$$
d \omega=\left[\left(\underline{\Phi}_{1}^{\prime}(t)\right)^{2}+\left(\underline{\Phi}_{2}^{\prime}(t)\right)^{2}+\left(\underline{\Phi}_{3}^{\prime}(t)\right)^{2}\right]^{1 / 2} d t
$$

The linear form $\ell[$.$] which represents the work of the external loads can be written$ (Part $1,(2.18)$ and $(3.13))$

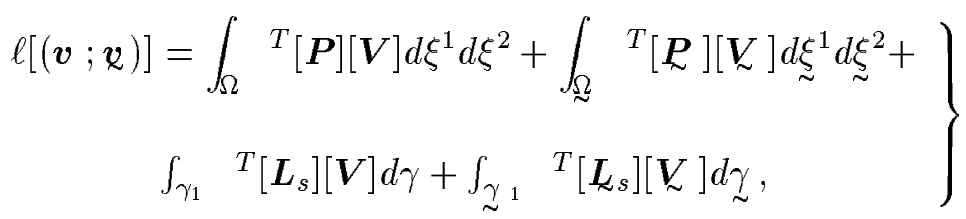

where

$$
{ }^{T}[\boldsymbol{P}]_{1 \times 12}=\sqrt{a}\left[\begin{array}{llllllllllll}
p^{1} & 0 & 0 & p^{2} & 0 & 0 & p^{3} & 0 & 0 & 0 & 0 & 0
\end{array}\right]
$$

and

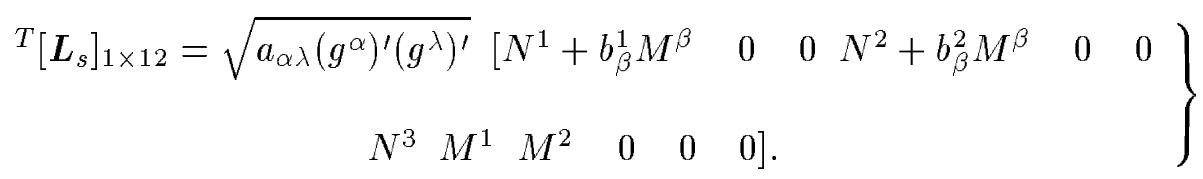

In the above equations, $p^{i}$ and $N^{i}$ denote respectively the covariant components of the body force resultant, of the resultant and of the resultant moment of the surface loads while $b_{\alpha}^{\beta}$ and $a$ are the second fundamental form and the determinant of the first fundamental form ; all these quantities are refered to the middle surface $\mathcal{S}$ and, by definition, $\boldsymbol{M}=M^{\alpha} \boldsymbol{a}_{\alpha} \times \boldsymbol{a}_{3}$. The vectors $[\boldsymbol{P}],\left[\boldsymbol{L}_{s}\right]$ are obtained by analogy.

\section{Construction of the discrete admissible spaces}

From now on, we shall assume that the domains $\Omega$ and $\Omega$ have polygonal boundaries. Then, we can exactly cover these domains by families of triangulations $\mathcal{T}_{h}$ and $\mathcal{T}_{h}$. Subsequently, we assume that these triangulations are compatible along the parts $\gamma$ and $\underset{\sim}{\gamma}$ of the boundaries $\partial \Omega$ and $\partial \underset{\sim}{\Omega}$ : in other words, their traces upon $\gamma$ and $\gamma$ are the images of a one dimensional triangulation $\mathcal{I}_{h}$ of the interval $\omega$ through the mappings $\boldsymbol{F}=\boldsymbol{\Phi}_{\mid \Gamma}^{-1} \circ \underline{\Phi}$ and $\boldsymbol{F}=\Phi^{-1}{ }_{\mid \Gamma} \circ \underline{\Phi}$ (Figure 1). From now on, for simplicity, we note $\Phi_{\mid \Gamma}^{-1}$ and $\Phi_{\sim}^{-1} \mid \Gamma$ by $\Phi^{-1}$ and $\underset{\sim}{\Phi^{-1}}$. All these triangulations are assumed to be regular in the sense that :

i) There exists constants $\sigma$ and $\sigma$ such that

$$
\forall K \in \mathcal{T}_{h}, \quad \frac{h_{K}}{\rho_{K}} \leq \sigma \text { and } \forall \underset{\sim}{K} \in \mathcal{T}_{h}, \quad \frac{h_{\mathcal{K}}}{\rho_{\mathcal{N}}} \leq \varepsilon,
$$

where $h_{K}=\operatorname{diam}(K), h_{K}=\operatorname{diam}(\underset{\sim}{K}), \rho_{K}=\sup \{\operatorname{diam}(S), S$ is a ball contained in $K\}$ and $\rho_{\underset{\sim}{K}}=\sup \{\operatorname{diam}(S), S$ is a ball contained in $\underset{\sim}{K}\}$.

ii) Let $h$ be a real number defined by

$$
h=\sup \left\{\max _{K \in \mathcal{T}_{h}} h_{K}, \max _{\underset{\sim}{K} \in \mathcal{T}_{h}} h_{\underset{\sim}{\sim}}, \max _{\underline{K} \in \underline{\mathcal{I}}_{h}} h_{\underline{K}}\right\},
$$

where $h_{\underline{K}}=\operatorname{diam}(\underline{K})$. Then, we assume that

$$
h \rightarrow 0 \text {. }
$$




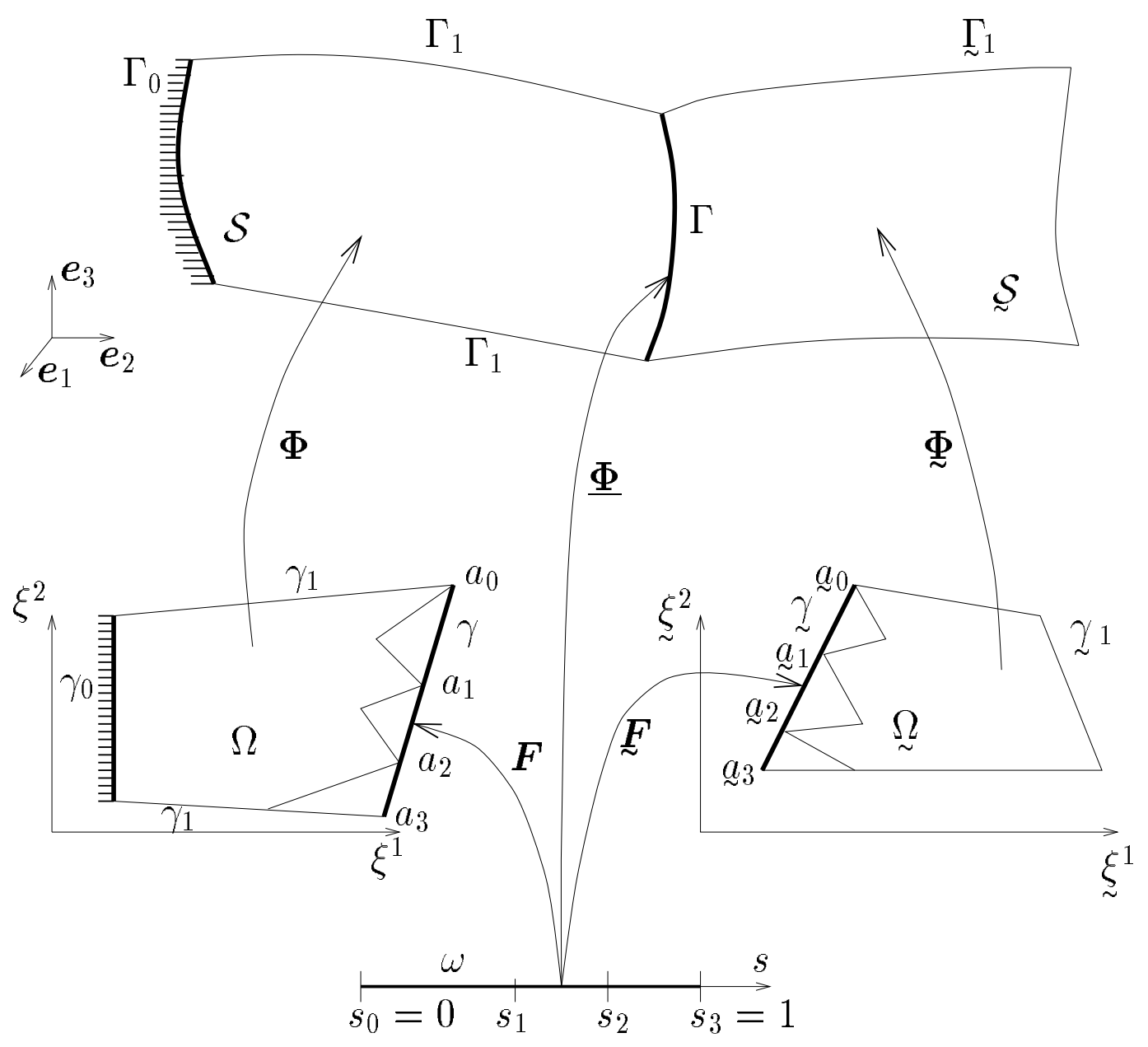

Fig. 1: Discretization of the hinge images

With the triangulations $\mathcal{T}_{h}$ and $\mathcal{T}_{h}$, we associate the finite element spaces $X_{h}$ and $X_{h}$ constructed from the Argyris triangle (Argyris-Fried-Scharpf (1968)), whose definition is recalled in Figure 2, and the spaces $V_{h}$ and $V_{h}$ :

$$
V_{h}=V_{h 1} \times V_{h 1} \times V_{h 2}, \quad V_{h}=\left(X_{h}\right)^{3}
$$

where

$$
V_{h 1}=\left\{v \in X_{h} ; v=0 \text { along } \gamma_{0}\right\} \text { and } V_{h 2}=\left\{v \in X_{h} ; v=v_{, \nu}=0 \text { along } \gamma_{0}\right\}
$$

and where $\nu$ is the outward unit normal vector to the boundary $\gamma_{0}$. These definitions and those of (Part 1, (3.7) and (3.8)) lead to the inclusions

$$
V_{h} \subset V \text { and } V_{h} \subset V \text {. }
$$




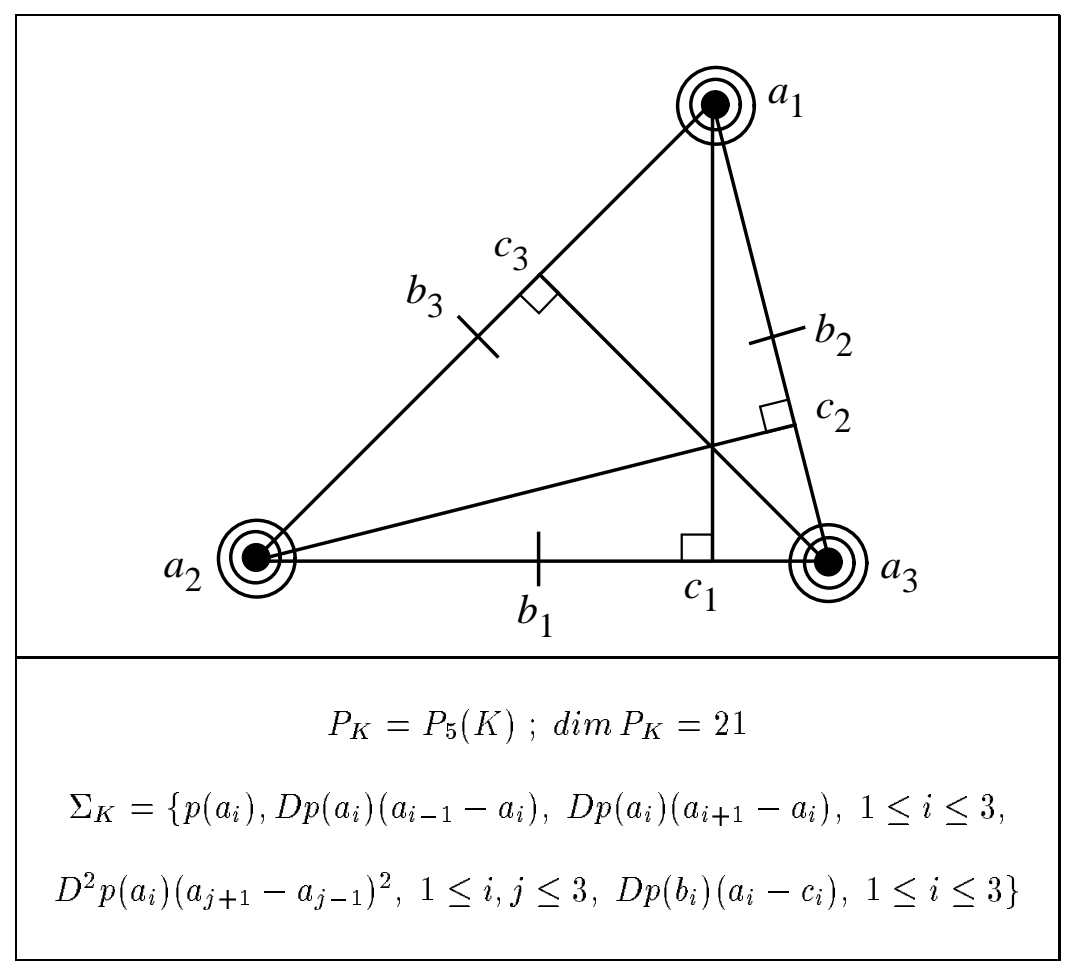

Fig. 2: The Argyris triangle

In order to build the discrete admissible spaces, we have to discretize the junction conditions ( equality of the displacements and equality of the tangential components of the rotations along the hinge), i.e., we have to express these conditions in terms of the degrees of freedom. This is a delicate step in the approximation of the continuous problems and it leads to the non-conformity of the method for the approximation of the transmission conditions along the hinge. The equality of the displacements along the hinge is a condition which appears for the elastic or the rigid junction problems as well. Thus we begin by studying the discretization of this condition.

\subsection{The discrete admissible space for the elastic junction problem}

First, let us recall the condition of continuity of the displacement along the hinge (Part 1, (2.31) 1$)$ :

$$
\boldsymbol{u}(\eta)=\underset{\sim}{\boldsymbol{u}}(\underset{\sim}{\eta}), \forall \eta \in \gamma, \quad \forall \underset{\sim}{\in} \underset{\sim}{\gamma} \text { such that } \boldsymbol{\Phi}(\eta)=\Phi(\underset{\sim}{\eta})
$$

The equation (3.5) is vectorial. For its discretization, we have to use components of displacements. The vectors $\boldsymbol{u}$ and $\boldsymbol{u}$ are expressed upon the contravariant bases $\left\{\boldsymbol{a}^{1}, \boldsymbol{a}^{2}, \boldsymbol{a}^{3}\right\}$ and $\left\{\underset{\sim}{\boldsymbol{a}^{1}}, \underset{\sim}{\boldsymbol{a}^{2}},{\underset{\sim}{\boldsymbol{a}}}^{3}\right\}$ which differ along the hinge. Therefore we have to write relation (3.5) upon one of these bases, for example $\left\{{\underset{\sim}{\boldsymbol{a}}}^{i}\right\}$ :

$$
u_{i}(\eta)=A_{i}^{j}(\eta, \underset{\sim}{\eta}) u_{j}(\eta)
$$

where $A_{i}^{j}(\eta, \underset{\sim}{\eta})=\boldsymbol{a}_{i}(\eta \underset{\sim}{ }) \cdot \boldsymbol{a}^{j}(\eta)$. 
In addition, we introduce the two mappings $\boldsymbol{F}: \bar{\omega}=[0,1] \rightarrow \gamma$ and $\boldsymbol{F}: \bar{\omega} \rightarrow \gamma$ which are assumed to be regular. The closed interval $\bar{\omega}$ is subdivided into $\mathrm{n}+1$ segments $\left[s_{p}, s_{p+1}\right]$, for $p=0, . ., n$ with $s_{0}=0$ and $s_{n+1}=1$. Thus $\boldsymbol{F}\left(s_{p}\right)=a_{p}$ and $\underset{\sim}{\boldsymbol{F}}\left(s_{p}\right)=a_{p}$ where $\left\{a_{p}\right\},\left\{a_{p}\right\}$ are the vertices of the triangles of $\mathcal{T}_{h}$ and $\mathcal{T}_{h}$ located along $\gamma$ and $\underset{\sim}{\gamma}$

By analogy with Zenisek (1981) who considered the approximation of nonhomogeneous boundary conditions, the approximation through Argyris triangle leads naturally to impose the following conditions :

$$
\left.\begin{array}{c}
u_{h i} \circ \boldsymbol{F}\left(s_{\ell}\right)=\underline{A}_{i}^{j} u_{h j} \circ \boldsymbol{F}\left(s_{\ell}\right), \\
\frac{d}{d s}\left(u_{h i} \circ \boldsymbol{F}\right)\left(s_{\ell}\right)=\frac{d}{d s}\left(\underline{A}_{i}^{j} u_{h j} \circ \boldsymbol{F}\right)\left(s_{\ell}\right), \\
\frac{d^{2}}{d s^{2}}\left(\underset{\sim}{u_{h i} \circ \boldsymbol{F}}\right)\left(s_{\ell}\right)=\frac{d^{2}}{d s^{2}}\left(\underline{A}_{i}^{j} u_{h j} \circ \boldsymbol{F}\right)\left(s_{\ell}\right),
\end{array}\right\}
$$

for $\ell=0, . ., n+1$ and where we have set for clarity $\underline{A}_{i}^{j}\left(s_{\ell}\right)=A_{i}^{j}\left(a_{\ell}, a_{\ell}\right)=A_{i}^{j}\left(\boldsymbol{F}\left(s_{\ell}\right), \boldsymbol{F}\left(s_{\ell}\right)\right)$.

Remark 3.1.1 : Components $u_{h i}$ and ${\underset{\sim}{h j}}_{h}$ are piecewise two dimensional five degree polynomials. Since we have supposed that $\gamma$ and $\gamma$ are rectilinear, the mappings $\boldsymbol{F}$ and $\boldsymbol{F}$ are affine. Thus, the composed mappings $\tilde{u}_{h i} \circ \boldsymbol{F}$ and $u_{h i} \circ \boldsymbol{F}$ are piecewise one dimensional five degree polynomials.

Now, we have to rewrite (3.6) in terms of degrees of freedom of Argyris triangle and thus to express these conditions on the reference domains $\Omega$ and $\underset{\sim}{\Omega}$. There is no problem for $(3.6)_{1}$ which can be directly written on the boundaries $\gamma$ or $\underset{\sim}{\gamma}$. For $(3.6)_{2}$ we use the following equation :

$$
\frac{d}{d s}\left(u_{h i} \circ \boldsymbol{F}\right)\left(s_{\ell}\right)=D u_{h i}\left(\boldsymbol{F}\left(s_{\ell}\right)\right) \cdot D \boldsymbol{F}\left(s_{\ell}\right)
$$

A unit tangent vector $\tau$ to $\gamma$ is given by : $\left|D \boldsymbol{F}\left(s_{\ell}\right)\right| \boldsymbol{\tau}\left(s_{\ell}\right)=D \boldsymbol{F}\left(s_{\ell}\right)$ so that by setting $u_{h i, \tau}\left(a_{\ell}\right)=D u_{h i}\left(a_{\ell}\right) \cdot \tau$, we obtain

$$
\frac{d}{d s}\left(u_{h i} \circ \boldsymbol{F}\right)\left(s_{\ell}\right)=\left|D \boldsymbol{F}\left(s_{\ell}\right)\right| u_{h i, \tau}\left(a_{\ell}\right) .
$$

With similar arguments and since $\boldsymbol{F}$ is affine, we have:

$$
\frac{d^{2}}{d s^{2}}\left(u_{h i} \circ \boldsymbol{F}\right)\left(s_{\ell}\right)=\left|D \boldsymbol{F}\left(s_{\ell}\right)\right|^{2} u_{h i, \tau \tau}\left(a_{\ell}\right) \text {. }
$$


Thus, the discrete junction conditions for elastic problem are obtained for $\ell=$ $0, \ldots, n+1$ by substituting (3.7) and (3.8) into relation (3.6) :

$$
\begin{aligned}
u_{h i}\left(a_{\ell}\right)= & \underline{A}_{i}^{j}\left(s_{\ell}\right) u_{h j}\left(a_{\ell}\right), \\
u_{h i, \tau}\left(a_{\ell}\right)= & \left\{\left(\frac{d}{d s} \underline{A}_{i}^{j}\right)\left(s_{\ell}\right) u_{h j}\left(a_{\ell}\right)+\left|D \boldsymbol{F}\left(s_{\ell}\right)\right| \underline{A}_{i}^{j}\left(s_{\ell}\right) u_{h j, \tau}\left(a_{\ell}\right)\right\} /\left|D \boldsymbol{F}\left(s_{\ell}\right)\right|, \\
u_{h i, \tau \tau}\left(a_{\ell}\right)= & \left\{\left(\frac{d^{2}}{d s^{2}} \underline{A}_{i}^{j}\right)\left(s_{\ell}\right) u_{h j}\left(a_{\ell}\right)+2\left|D \boldsymbol{F}\left(s_{\ell}\right)\right|\left(\frac{d}{d s} \underline{A}_{i}^{j}\right)\left(s_{\ell}\right) u_{h i, \tau}\left(a_{\ell}\right)\right. \\
& \left.+\left|D \boldsymbol{F}\left(s_{\ell}\right)\right|^{2} \underline{A}_{i}^{j}\left(s_{\ell}\right) u_{h j, \tau \tau}\left(a_{\ell}\right)\right\} /\left|D \boldsymbol{F}\left(s_{\ell}\right)\right|^{2} .
\end{aligned}
$$

Thus, the admissible discrete displacement space for the elastic junction problem is defined by :

$$
\left.\begin{array}{rl}
W_{h e l}=\left\{\left(\boldsymbol{v}_{h} ; \boldsymbol{v}_{h}\right) \in V_{h} \times V_{h},\right. \text { such that relations (3.9) are verified at the } \\
& \text { corresponding vertices } \left.\left\{a_{\ell}\right\} \text { and }\left\{a_{\ell}\right\} \text { located on } \gamma \text { and } \underset{\sim}{\gamma}\right\}
\end{array}\right\}
$$

\subsection{The discrete admissible space for the rigid junction problem}

We proceed by similarity for the rigid junction problem which amounts to discretize the second condition (Part $1,(2.30)_{2}$ ) related to the equality of the rotations. The approximation through Argyris triangle leads to impose the following conditions :

$$
\left.\begin{array}{l}
{\left[n^{\beta}\left(u_{h 3, \beta}+b_{\beta}^{\alpha} u_{h \alpha}\right)\right] \circ \boldsymbol{F}\left(s_{\ell}\right)=\left[(\boldsymbol{t} \cdot \underset{\sim}{\boldsymbol{t}}){\underset{\sim}{n}}^{\beta}\left(u_{h 3, \beta}+{\underset{\sim}{b}}_{\beta}^{\alpha} u_{h \alpha}\right)\right] \circ \boldsymbol{F}\left(s_{\ell}\right)} \\
{\left[n^{\beta}\left(u_{h 3, \beta}+b_{\beta}^{\alpha} u_{h \alpha}\right)\right] \circ \boldsymbol{F}\left(q_{\jmath}\right)=\left[(\boldsymbol{t} \cdot \underset{\sim}{\boldsymbol{t}}){\underset{\sim}{n}}^{\beta}\left(u_{h 3, \beta}+{\underset{\sim}{b}}_{\beta}^{\alpha} u_{h \alpha}\right)\right] \circ \boldsymbol{F}\left(q_{\jmath}\right)} \\
\frac{d}{d s}\left\{\left[n^{\beta}\left(u_{h 3, \beta}+b_{\beta}^{\alpha} u_{h \alpha}\right)\right] \circ \boldsymbol{F}\right\}\left(s_{\ell}\right)=\frac{d}{d s}\left\{\left[(\boldsymbol{t} \cdot \underset{\sim}{\boldsymbol{t}}) \underset{\sim}{n^{\beta}}\left({\underset{\sim}{h 3, \beta}}_{h}+{\underset{\sim}{b}}_{\beta}^{\alpha} u_{h \alpha}\right)\right] \circ \boldsymbol{F}\right\}\left(s_{\ell}\right)
\end{array}\right\}
$$

for $\ell=0, . ., n+1$ and $\jmath=0, \ldots, n$, where $\boldsymbol{n}=n^{\alpha} \boldsymbol{a}_{\alpha}$ is the outward unit normal vector to the junction $\Gamma$ in the tangent plane to $\mathcal{S}$ and $q_{\jmath}$ is the midpoint of $\left[s_{\ell}, s_{\ell+1}\right]$.

In order to obtain normal and tangential derivatives, we use the relation

$$
v_{3, \beta}=\tau_{\beta} v_{3, \tau}+\nu_{\beta} v_{3, \nu}
$$


where $\boldsymbol{\tau}$ and $\boldsymbol{\nu}$ are respectively the unit tangent vector and the outward unit normal vector to the triangle of $\mathcal{T}_{h}$ which has a side on $\gamma$. Relations (3.11) give

$$
\begin{aligned}
& n^{\beta}\left(u_{h 3, \beta}+b_{\beta}^{\alpha} u_{h \alpha}\right)\left(a_{\ell}\right)=(\boldsymbol{t} \cdot \underset{\sim}{\boldsymbol{t}}) \underline{\sim}^{\beta}\left(u_{h 3, \beta}+{\underset{\sim}{\beta}}_{\beta}^{\alpha} u_{h \alpha}\right)\left(a_{\ell}\right) \\
& n^{\beta}\left(\tau_{\beta} u_{h 3, \tau}+\nu_{\beta} u_{h 3, \nu}+b_{\beta}^{\alpha} u_{h \alpha}\right)\left(b_{\jmath}\right)=(\boldsymbol{t} \cdot \underset{\sim}{\boldsymbol{t}}) \underset{\sim}{n^{\beta}}\left(\mathcal{I}_{\beta} u_{h 3, \tau}+k_{\beta} u_{h 3, \nu}+{\underset{\sim}{\beta}}_{\beta}^{\alpha} u_{h \alpha}\right)\left(b_{\jmath}\right) \\
& \left|D \boldsymbol{F}\left(s_{\ell}\right)\right|\left\{n_{, \tau}^{\beta}\left(u_{h 3, \beta}+b_{\beta}^{\alpha} u_{h \alpha}\right)+n^{\beta}\left(\tau_{\beta} u_{h 3, \tau \tau}+\nu_{\beta} u_{h 3, \nu \tau}+b_{\beta}^{\alpha} u_{h \alpha, \tau}+\right.\right.
\end{aligned}
$$

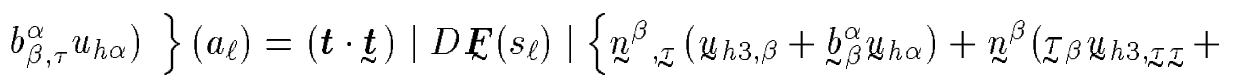

$$
\begin{aligned}
& \left.\left.\nu_{\beta} u_{h 3, k \tau}+{\underset{\sim}{\beta}}_{\beta}^{\alpha} u_{h \alpha, \tau}+{\underset{\sim}{\beta, \tau}}_{\beta, \tau}^{\alpha} u_{h \alpha}\right)\right\}\left(a_{\ell}\right)
\end{aligned}
$$

for $\ell=0, . ., n+1$ and $\jmath=0, . ., n ; \tau_{\alpha}$ are the components of the unit tangent vector used in (3.7) and $b_{\jmath}$ is the midpoint of $\left[a_{\ell}, a_{\ell+1}\right]$.

Thus, the admissible discrete displacement space for the rigid junction problem is defined by :

$$
\left.\begin{array}{c}
W_{\text {hrig }}=\left\{\left(\boldsymbol{v}_{h} ; \boldsymbol{v}_{h}\right) \in V_{h} \times V_{h},\right. \text { such that relations (3.9) and (3.12) are verified } \\
\text { at the corresponding vertices } \left.\left\{a_{\ell}\right\},\left\{a_{\ell}\right\},\left\{b_{\ell}\right\} \text { and }\left\{b_{\ell}\right\} \text { located on } \gamma \text { and } \underset{\sim}{\gamma}\right\}
\end{array}\right\}
$$

Remark 3.2.1. This discretization of junction conditions involves the nonconformity of the approximation, i.e.,

$$
W_{\text {hel }} \not \subset \quad W_{e l} \text { and } W_{\text {hrig }} \not \subset W_{\text {rig }} \text {. }
$$

Since the nonconformity just appears along the hinge while the method remains conform for all the other terms defined on $\Omega$ and $\underset{\sim}{\Omega}$, we say that the approximation method is pseudo-conforming.

Remark 3.2.2. In relations (3.12), the quantities $u_{h 3, \tau}\left(b_{\jmath}\right), u_{h \alpha}\left(b_{\jmath}\right)$ and the associated quantities on $\mathcal{S}$, are not degrees of freedom of Argyris triangle, but they can be expressed from them through the definition of the interpolating function.

\section{First discrete problem for elastic junction problem}

From now on, we only consider the elastic junction problem. The rigid one could be considered similarly ; we will give the corresponding main results in Section 6 .

\subsection{Definition of the first discrete problem}

The following variational formulation takes only into account the finite element approximation ; the effect of the numerical integration will be analyzed in Section 
5.

Find $\left(\boldsymbol{\boldsymbol { u }}_{h}^{k} ;{\underset{\sim}{\boldsymbol{*}}}_{h}^{k}\right) \in W_{\text {hel }}$ such that

$$
\begin{aligned}
& a\left[\left(\ddot{\boldsymbol{u}}_{h}^{k} ;{\underset{\sim}{\boldsymbol{*}}}_{h}^{k}\right),\left(\boldsymbol{v}_{h} ; \boldsymbol{v}_{h}\right)\right]+k b\left[\left(\underline{\boldsymbol{v}}_{h}^{k} ; \underline{\sim}_{h}^{*}\right),\left(\underline{\boldsymbol{v}}_{h} ; \underline{\sim}_{h}^{\boldsymbol{v}}\right)\right]=\ell\left[\left(\boldsymbol{v}_{h} ; \boldsymbol{v}_{h}\right)\right]+f\left[\left(\boldsymbol{v}_{h} ; \boldsymbol{v}_{h}\right)\right], \\
& \forall\left(\boldsymbol{v}_{h} ; \boldsymbol{v}_{h}\right) \in W_{h e l}, k \text { constant }>0,
\end{aligned}
$$

where $\underline{\boldsymbol{v}}_{h}^{k}=\boldsymbol{v}_{h}^{k} \circ \boldsymbol{F}, \underline{\boldsymbol{v}}_{h}^{k}={\underset{\sim}{\boldsymbol{v}}}_{h}^{k} \circ \boldsymbol{F}$ and where the space $W_{h e l}$ is defined by relation (3.10).

By comparison with (Part 1, (3.10)) we have introduced a new linear form $f[$. which takes into account the non-conformity of the approximation along the hinge, i.e.,

$$
f[(\boldsymbol{v} ; \boldsymbol{v})]=\int_{\Gamma}\{N \cdot \boldsymbol{v}-N \cdot \boldsymbol{v}\} d \Gamma=\int_{\gamma} \boldsymbol{N} \cdot \boldsymbol{v} d \gamma+\int_{\underset{\sim}{\gamma}} \boldsymbol{N} \cdot \boldsymbol{v} d \underset{\sim}{\gamma}
$$

where $N$ and $N$ are the resultants of the surface load. This form is identically zero when $(\boldsymbol{v} ; \boldsymbol{v}) \in W_{e l}$ while it is generally different from zero when applied to elements $\left(\boldsymbol{v}_{h} ; \boldsymbol{v}_{h}\right) \in W_{h e l}$. In that case, we rewrite in matrix form

$$
f\left[\left(\boldsymbol{v}_{h} ; \boldsymbol{v}_{h}\right)\right]=\int_{\gamma}{ }^{T}[\boldsymbol{N}]\left[\boldsymbol{V}_{h}\right] d \gamma+\int_{\mathcal{\sim}}{ }^{T}[\boldsymbol{N}]\left[\boldsymbol{V}_{h}\right] d \underset{\sim}{\gamma},
$$

where the column vectors $\left[\boldsymbol{V}_{h}\right]$ and $\left[\boldsymbol{V}_{h}\right]$ are defined in $(2.2)$, and where we have set

$$
{ }^{T}[N]_{1 \times 12}=\left[\begin{array}{llllllllllll}
N^{1} & 0 & 0 & N^{2} & 0 & 0 & N^{3} & 0 & 0 & 0 & 0 & 0
\end{array}\right]
$$

(and a similar expression for $[\boldsymbol{N}]$ ). The introduction of this linear form $f[$.$] in (4.1)$ leads to a simplification in the abstract error estimate ( see Paragraph 4.3).

\subsection{Uniform ellipticity}

In this paragraph, we prove the existence and uniqueness of a solution for problem (4.1). That leads to show the uniform $W_{h e l}$-ellipticity with respect to $h$ of the bilinear form $a[.,]+.k b[.,$.$] .$

First, let us recall some definitions introduced in Part 1. Let space $E$ be

$$
E=\left(H^{1}(\Omega)\right)^{2} \times H^{2}(\Omega) \times\left(H^{1}(\underset{\sim}{\Omega})\right)^{2} \times H^{2}(\underset{\sim}{\Omega})
$$

equipped with the norm

$$
\|(\boldsymbol{v} ; \boldsymbol{v})\|_{E}=\left\{\left\|v_{1}\right\|_{1, \Omega}^{2}+\left\|v_{2}\right\|_{1, \Omega}^{2}+\left\|v_{3}\right\|_{2, \Omega}^{2}+\left\|v_{1}\right\|_{1, \Omega}^{2}+\left\|\underline{v}_{2}\right\|_{1, \Omega}^{2}+\left\|v_{3}\right\|_{2, \Omega}^{2}\right\}^{1 / 2} .
$$

The space $W_{h e l}$, defined in (3.10), is a linear subspace of $E$ and the above mapping is a norm on $W_{\text {hel }}$. 
Lemma 4.2.1: The application $\left(\boldsymbol{v}_{h} ; \boldsymbol{v}_{h}\right) \in W_{h e l} \rightarrow\left\|\left(\boldsymbol{v}_{h} ; \boldsymbol{v}_{h}\right)\right\|_{W_{h e l}}$ is a norm on $W_{\text {hel }}$ where

$$
\left\|\left(\boldsymbol{v}_{h} ; \boldsymbol{v}_{h}\right)\right\|_{W_{h e l}}=\left\{a\left[\left(\boldsymbol{v}_{h} ; \boldsymbol{v}_{h}\right),\left(\boldsymbol{v}_{h} ; \boldsymbol{v}_{h}\right)\right]+k b\left[\left(\boldsymbol{v}_{h} ; \boldsymbol{v}_{h}\right),\left(\boldsymbol{v}_{h} ; \boldsymbol{v}_{h}\right)\right]\right\}^{1 / 2}
$$

In this expression, we consider the definition of the bilinear form $b[.,$.$] given in (2.3).$

\section{Proof :}

This mapping is clearly a semi-norm. Thus we just have to show that :

$$
\left\|\left(\boldsymbol{v}_{h} ; \boldsymbol{v}_{h}\right)\right\|_{W_{h e l}}=0 \Rightarrow\left(\boldsymbol{v}_{h} ; \boldsymbol{v}_{h}\right)=(\mathbf{0}, \mathbf{0}) \text { in } \Omega \times \underset{\sim}{\Omega} .
$$

The assumption $\left\|\left(\boldsymbol{v}_{h} ; \boldsymbol{v}_{h}\right)\right\|_{W_{h e l}}=0$ immediately involves :

i) $\int_{\Omega} e E^{\alpha \beta \lambda \mu}\left[\gamma_{\alpha \beta}\left(\boldsymbol{v}_{h}\right) \gamma_{\lambda \mu}\left(\boldsymbol{v}_{h}\right)+\frac{e^{2}}{12} \rho_{\alpha \beta}\left(\boldsymbol{v}_{h}\right) \rho_{\lambda \mu}\left(\boldsymbol{v}_{h}\right)\right] \sqrt{a} d \xi^{1} d \xi^{2}=0$ so that the boundary condition on $\gamma_{0}$ gives $\boldsymbol{v}_{h}=\mathbf{0}$ in $\Omega$;

ii) the discrete junction conditions (3.9) imply

$$
\underline{\sim}_{h i}\left(a_{\ell}\right)=\underline{v}_{h i, \tau}\left(a_{\ell}\right)=\underline{v}_{h i, \tau \tau}\left(a_{\ell}\right)=0
$$

for $\ell=0, \ldots, n+1$, where $\left\{a_{\ell}\right\}$ is the set of vertices located on $\underset{\sim}{\gamma}$. Since ${\underset{\sim}{h i}}_{h i}$ are five degree polynomials upon each triangle side located on $\gamma$, relations (4.3) imply tro ${\underset{\sim}{h i}}=0$ on $\underset{\sim}{\gamma}$. Moreover, $(\operatorname{Part} 1,(2.15),(3.12))$ and $\tilde{b}\left[\left(\boldsymbol{v}_{h} ; \boldsymbol{v}_{h}\right),\left(\boldsymbol{v}_{h} ; \boldsymbol{v}_{h}\right)\right]=$

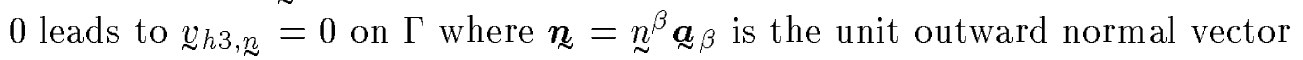
to $\Gamma$ located in the tangent plane to $\mathcal{S}$.

Here, our purpose is to obtain clamped condition on $\underset{\sim}{\gamma}$, i.e., $\underline{v}_{h 3, \nu}=0$ on $\underset{\sim}{\gamma}$. We point out that $\underline{v}_{h 3, n}$ and $\underline{v}_{h 3, \nu}$ are not the same quantities. Indeed, $\boldsymbol{n}$ is defined along $\Gamma$ whereas $\underset{\sim}{\boldsymbol{\nu}}$ is defined along $\underset{\sim}{\gamma}$. The relation between these two quantities is :

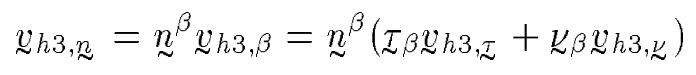

Moreover, note that $\underline{\sim}_{h 3}=0$ on $\underset{\sim}{\gamma}$ implies $\underline{v}_{h 3, \tau}=0$ on $\underset{\sim}{\gamma}$. Thus, by using in addition relation (4.4) and the assumption $v_{h 3, n}=0$ on $\Gamma$ and noticing that the quantity $n^{\beta} \nu_{\beta}$ is different from zero, we obtain the required clamped condition $\underline{v}_{h 3, \nu}=0$ on $\underset{\sim}{\gamma}$. Then, we obtain $\boldsymbol{x}_{h}=\mathbf{0}$ in $\underset{\sim}{\Omega}$.

Lemma 4.2.2 : Upon the space $W_{\text {hel }}$, the norms $\|(\boldsymbol{v} ; \boldsymbol{v})\|_{E}$ and $\|(\boldsymbol{v} ; \boldsymbol{v})\|_{W_{h e l}}$ are uniformly equivalent with respect to $h$.

Proof : The proof of this lemma is based on the same arguments to those of Part 1, Theorem 3.1.1. The uniform-ellipticity comes from the inclusions (3.4) which allow us to choose the same constants than for the continuous problem (Part 1, (3.10)). 
Theorem 4.2.1: Problem (4.1) has one and only one solution.

Proof : Since the bilinear form $a[.,]+.k b[.,$.$] is uniformly W_{h e l}$-elliptic and uniformly continuous with respect to $h$, and since the linear form $\ell[]+.f[$.$] is clearly uniformly$ continuous, we have just to apply the Lax-Milgram lemma to conclude.

\subsection{Abstract error estimate}

The abstract error estimate is used in practice to obtain asymptotic error estimate. In the following theorem, the estimation is restricted to the usual approximation theory term $\inf _{\left(\boldsymbol{v}_{h} ; \boldsymbol{q}_{h}\right) \in W_{h e l}}\left\|\left(\boldsymbol{u}^{k} ; \underset{\sim}{\boldsymbol{u}^{k}}\right)-\left(\boldsymbol{v}_{h} ; \boldsymbol{v}_{h}\right)\right\|_{E}$ which is known as soon as a finite element approximation is chosen.

Theorem 4.3.1 : Let us consider the discrete problem (4.1) for which the bilinear form $a[.,]+.k b[.,$.$] is uniformly W_{\text {hel }}$-elliptic, i.e., there exists a constant $\beta>0$, independent of $h$, such that :

$a\left[\left(\boldsymbol{v}_{h} ; \boldsymbol{v}_{h}\right),\left(\boldsymbol{v}_{h} ; \boldsymbol{v}_{h}\right)\right]+k b\left[\left(\underline{\boldsymbol{v}}_{h} ; \underline{\sim}_{h}\right),\left(\underline{\boldsymbol{v}}_{h} ; \underline{\underline{v}}_{h}\right)\right] \geq \beta\left\|\left(\boldsymbol{v}_{h} ; \boldsymbol{v}_{h}\right)\right\|_{E}^{2}, \quad \forall\left(\boldsymbol{v}_{h} ; \boldsymbol{v}_{h}\right) \in W_{h e l}$

We suppose, moreover, that there exists a constant $M>0$, independent of $h$, such that

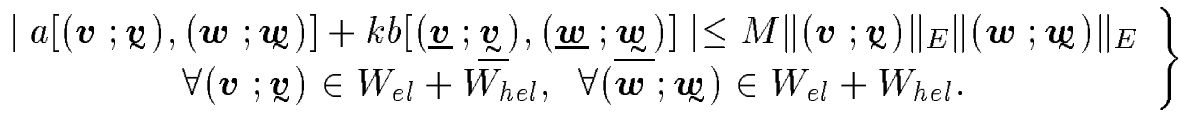

Then, there exists a constant $C$, independent of $h$, such that

$$
\left\|\left(\boldsymbol{u}^{k} ;{\underset{\sim}{\boldsymbol{u}^{k}}}^{k}\right)-\left(\boldsymbol{u}_{h}^{k} ; \underset{\sim}{\boldsymbol{u}_{h}^{k}}\right)\right\|_{E} \leq C \inf _{\left(\boldsymbol{v}_{h} ; \boldsymbol{v}_{h}\right) \in W_{h e l}}\left\|\left(\boldsymbol{u}^{k} ;{\underset{\sim}{\boldsymbol{u}^{k}}}^{k}\right)-\left(\boldsymbol{v}_{h} ; \boldsymbol{v}_{h}\right)\right\|_{E}
$$

where $\left(\boldsymbol{u}^{k} ;{\underset{\boldsymbol{u}}{k}}^{k}\right)$ (resp. $\left.\left(\boldsymbol{\boldsymbol { u }}_{h}^{k} ;{\underset{\sim}{\boldsymbol{*}}}_{h}^{k}\right)\right)$ denotes the solution of the continuous problem (Part 1, (3.10)) (resp. of the discrete problem (4.1)).

Proof : Lemma 4.2.2 involves that relation (4.5) is verified. Likewise, relation (4.6) is a consequence of continuity properties of the bilinear forms $a[.,$.$] and b[.,$.$] . Let$ $\left(\boldsymbol{v}_{h} ; \boldsymbol{x}_{h}\right)$ be any element of the space $W_{h e l} ;$ we can write by using relations (4.1) and (4.5)

$$
\begin{aligned}
& \beta\left\|\left(\boldsymbol{u}_{h}^{k} ;{\underset{\sim}{*}}_{h}^{k}\right)-\left(\boldsymbol{v}_{h} ; \boldsymbol{v}_{h}\right)\right\|_{E}^{2} \leq a\left[\left(\boldsymbol{u}^{k} ;{\underset{\sim}{\boldsymbol{u}^{k}}}^{k}\right)-\left(\boldsymbol{v}_{h} ; \boldsymbol{v}_{h}\right),\left(\boldsymbol{\boldsymbol { u }}_{h}^{k} ;{\underset{\sim}{\boldsymbol{*}}}_{h}^{k}\right)-\left(\boldsymbol{v}_{h} ; \boldsymbol{v}_{h}\right)\right] \\
& +k b\left[\left(\underline{\underline{\boldsymbol{u}}}^{k} ; \underline{\underline{\boldsymbol{u}}}^{k}\right)-\left(\underline{\boldsymbol{v}}_{h} ;{\underset{\sim}{\boldsymbol{v}}}_{h}\right),\left(\underline{\boldsymbol{\boldsymbol { v }}}_{h}^{k} ;{\underset{\sim}{\boldsymbol{v}}}_{h}^{k}\right)-\left(\underline{\boldsymbol{v}}_{h} ;{\underset{\sim}{\boldsymbol{v}}}_{h}\right)\right] \\
& -a\left[\left(\boldsymbol{u}^{k} ; \underline{\sim}^{k}\right),\left(\ddot{\boldsymbol{u}}_{h}^{k} ;{\underset{\sim}{\boldsymbol{*}}}_{h}^{k}\right)-\left(\boldsymbol{v}_{h} ; \boldsymbol{v}_{h}\right)\right]-k b\left[\left(\underline{\boldsymbol{u}}^{k} ; \underline{\sim}^{k}\right),\left(\underline{\underline{\boldsymbol{v}}}_{h}^{k} ; \underline{\sim}_{h}^{\boldsymbol{*}}{ }_{h}^{k}\right)-\left(\underline{\boldsymbol{v}}_{h} ; \underline{\underline{\boldsymbol{v}}}_{h}\right)\right] \\
& +\ell\left[\left(\boldsymbol{\boldsymbol { u }}_{h}^{k} ;{\underset{\sim}{\boldsymbol{*}}}_{h}^{k}\right)-\left(\boldsymbol{v}_{h} ; \boldsymbol{v}_{h}\right)\right]+f\left[\left(\boldsymbol{\boldsymbol { u }}_{h}^{k} ;{\underset{\sim}{\boldsymbol{*}}}_{h}^{k}\right)-\left(\boldsymbol{v}_{h} ; \boldsymbol{v}_{h}\right)\right]
\end{aligned}
$$


so that with the continuity property $(4.6)$, we obtain :

$$
\begin{aligned}
& \beta\left\|\left(\boldsymbol{u}_{h}^{k} ;{\underset{\sim}{*}}_{h}^{k}\right)-\left(\boldsymbol{v}_{h} ; \boldsymbol{v}_{h}\right)\right\|_{E} \leq M\left\|\left(\boldsymbol{u}^{k} ;{\underset{\sim}{\boldsymbol{u}}}^{k}\right)-\left(\boldsymbol{v}_{h} ; \boldsymbol{v}_{h}\right)\right\|_{E}+ \\
& \sup _{\left(\boldsymbol{w}_{h} ; \boldsymbol{w}_{h}\right) \in W_{h e l}} \frac{\left|a\left[\left(\boldsymbol{u}^{k} ; \underline{\sim}^{k}\right),\left(\boldsymbol{w}_{h} ; \boldsymbol{w}_{h}\right)\right]+k b\left[\left(\underline{\boldsymbol{u}}^{k} ;{\underset{\sim}{\boldsymbol{u}}}^{k}\right),\left(\underline{\boldsymbol{w}}_{h} ;{\underset{\sim}{\boldsymbol{w}}}_{h}\right)\right]-\ell\left[\left(\boldsymbol{w}_{h} ; \boldsymbol{w}_{h}\right)\right]-f\left[\left(\boldsymbol{w}_{h} ; \boldsymbol{w}_{h}\right)\right]\right|}{\left\|\left(\boldsymbol{w}_{h} ; \boldsymbol{w}_{h}\right)\right\|_{E}} .
\end{aligned}
$$

Now, let us obtain a new expression for $a\left[\left(\boldsymbol{u}^{k} ; \underline{\sim}^{k}\right),\left(\boldsymbol{w}_{h} ; \boldsymbol{w}_{h}\right)\right]+k b\left[\left(\underline{\boldsymbol{u}}^{k} ; \underline{\underline{\boldsymbol{u}}}^{k}\right),\left(\underline{\boldsymbol{w}}_{h} ; \underline{\underline{\boldsymbol{w}}}_{h}\right)\right]$. For that we come back to the equilibrium equations of the junction problem given in (Part 1, (2.27)-(2.28)). Making the product of these equations by test functions $\left(\boldsymbol{w}_{h}, \boldsymbol{w}_{h}\right) \in W_{h e l}$ and using Green's formula, we finally get with notations introduced in $(4.1)$

$$
\begin{aligned}
a\left[\left(\boldsymbol{u}^{k} ; \underline{\boldsymbol{u}}^{k}\right),\left(\boldsymbol{w}_{h} ; \boldsymbol{w}_{h}\right)\right]+k b\left[\left(\underline{\boldsymbol{u}}^{k} ; \underline{\sim}^{k}\right),\left(\underline{\boldsymbol{w}}_{h} ; \underline{\sim}_{\sim}^{\boldsymbol{w}}\right)\right] \\
\quad=\ell\left[\left(\boldsymbol{w}_{h} ; \boldsymbol{w}_{h}\right)\right]+\int_{\gamma} \boldsymbol{N} \cdot \boldsymbol{w}_{h} d \gamma+\int_{\mathcal{\sim}} N \cdot \boldsymbol{w}_{h} d \gamma \\
=\ell\left[\left(\boldsymbol{w}_{h} ; \boldsymbol{w}_{h}\right)\right]+f\left[\left(\boldsymbol{w}_{h} ; \boldsymbol{w}_{h}\right)\right],
\end{aligned}
$$

so that the second term in the above estimation disappears.

To conclude, it remains to use the triangular inegality and to take the minimum with respect to $\left(\boldsymbol{v}_{h} ; \boldsymbol{x}_{h}\right) \in W_{h e l}$.

Remark 4.3.1: The relation (4.7) allows us to cancel the consistency term that we usually find in the abstract error estimate associated with nonconforming finite element method. Here, the nonconformity only appears along the hinge $\Gamma$; its effect is circumvent by the introduction of the linear form $f[$.$] in (4.1).$

Another discrete problem could also be considered by dropping term $f[$.] in (4.1). It should be different from problem (4.1) and would lead to a more classical abstract error estimate including a consistency term based on the linear form $f[$.$] . The$ solution of such a problem would be really closed to that of problem (4.1).

\section{Second discrete problem : additional effect of nume- rical integration}

\subsection{Definition of the second discrete problem}

The integrals defined over the domains $\Omega$ and $\underset{\sim}{\Omega}$ have to be evaluated over all the triangles $K \in \mathcal{T}_{h}$ and $K \in \mathcal{T}_{h}$ and they are seldom exactly computed in practice. One rather use numerical integration schemes. Then, let us consider a numerical integration scheme defined over a reference triangle $\hat{K}$ (for more details see Ciarlet (1978)):

$$
\int_{\hat{K}} \hat{\phi}(\hat{x}) d \hat{x} \sim \sum_{\ell=1}^{L} \hat{\omega}_{\ell} \hat{\phi}\left(\hat{b}_{\ell}\right) .
$$


All the integrals appearing in the expressions of $a[.,$.$] and \ell[$.$] are of the form$ $\int_{K} \phi(x) d x$. We use the usual correspondence between $\phi$ and $\hat{\phi}$ through the affine invertible mapping

$$
F_{K} \quad: \hat{x} \in \hat{K} \rightarrow F_{K}(\hat{x})=B_{K} \hat{x}+b_{K} \in K,
$$

where $B_{K}$ is an invertible matrix, $b_{K}$ is a vector of $\mathbb{R}^{2}$ such that $F_{K}\left(\hat{a}_{i}\right)=a_{i}, i=$ $1,2,3$, where $\hat{a}_{i}, a_{i}$ are the vertices of the triangles $\hat{K}$ and $K$. Then, the numerical integration scheme over the triangle $\hat{K}$ automatically induces a numerical integration scheme over $K$, namely

$$
\int_{K} \phi(x) d x \sim \sum_{\ell=1}^{L} \omega_{\ell, K} \phi\left(b_{\ell, K}\right)
$$

with $\omega_{\ell, K}=\operatorname{det}\left(B_{K}\right) \hat{\omega}_{\ell}$ and $b_{\ell, K}=F_{K}\left(\hat{b}_{\ell}\right), 1 \leq \ell \leq L$. Moreover, we define the error functionals :

$$
\hat{E}(\hat{\phi})=\int_{\hat{K}} \hat{\phi}(\hat{\xi}) d \hat{\xi}-\sum_{\ell=1}^{L} \hat{\omega}_{\ell} \hat{\phi}\left(\hat{b}_{\ell}\right), \quad E_{K}(\phi)=\int_{K} \phi(\xi) d \xi-\sum_{\ell=1}^{L} \omega_{\ell, K} \phi\left(b_{\ell, K}\right),
$$

so that

$$
E_{K}(\phi)=\operatorname{det} B_{K} \hat{E}(\hat{\phi}) .
$$

We define similar functions for the domain $\underset{\sim}{\Omega}$ and for the triangles $\underset{\sim}{K} \in \mathcal{T}_{h}$. Finally, we introduce a numerical integration scheme over each triangle side $\hat{K}^{\prime}$ located upon the boundaries $\gamma, \underset{\sim}{\gamma}, \gamma_{1}, \underset{\sim}{\gamma}, \omega:$

$$
\int_{\hat{K}^{\prime}} \hat{\phi}^{\prime}(\hat{s}) d \hat{s} \sim \sum_{\ell=1}^{L^{\prime}} \hat{\omega}_{\ell}^{\prime} \hat{\phi}^{\prime}\left(\hat{b}_{\ell}^{\prime}\right)
$$

Thus, we use the correspondence between $\hat{\phi}^{\prime}$ and $\phi^{\prime}$ through the affine invertible mapping

$$
G_{K^{\prime}}: \hat{s} \in \hat{K}^{\prime} \rightarrow G_{K^{\prime}}(\hat{s})=\alpha \hat{s}+\beta \in K^{\prime},
$$

where $\alpha \neq 0$. We have $G_{K^{\prime}}\left(\hat{s}_{\alpha}\right)=s_{\alpha}, \alpha=1,2$ where $\hat{s}_{\alpha}, s_{\alpha}$ are the corresponding vertices of the sides $\hat{K}^{\prime}$ and $K^{\prime}$. Then we have a numerical integration scheme over the segment $K^{\prime}$

$$
\int_{K^{\prime}} \phi^{\prime}(s) d s \sim \sum_{\ell=1}^{L^{\prime}} \omega_{\ell, K^{\prime}} \phi^{\prime}\left(b_{\ell, K^{\prime}}\right)
$$

with $\omega_{\ell, K^{\prime}}=\alpha \hat{\omega}_{\ell}^{\prime}$ and $b_{\ell, K^{\prime}}=G_{K^{\prime}}\left(\hat{b}_{\ell}^{\prime}\right), 1 \leq \ell \leq L^{\prime}$ and the associated error functionnal

$$
\hat{E}^{\prime}\left(\hat{\phi}^{\prime}\right)=\int_{\hat{K}^{\prime}} \hat{\phi}^{\prime}(\hat{s}) d \hat{s}-\sum_{\ell=1}^{L^{\prime}} \hat{\omega}_{\ell}^{\prime} \hat{\phi}^{\prime}\left(\hat{b}_{\ell}^{\prime}\right), \quad E_{K^{\prime}}^{\prime}\left(\phi^{\prime}\right)=\int_{K^{\prime}} \phi^{\prime}(s) d s-\sum_{\ell=1}^{L^{\prime}} \omega_{\ell, K^{\prime}} \phi^{\prime}\left(b_{\ell, K^{\prime}}\right),
$$

so that

$$
E_{K^{\prime}}^{\prime}\left(\phi^{\prime}\right)=\alpha \hat{E}^{\prime}\left(\hat{\phi}^{\prime}\right)
$$


Now, we can give the expression of the second discrete problem which takes into account the additional effect of the numerical integration.

Find $\left(\boldsymbol{u}_{h}^{k} ; \boldsymbol{u}_{h}^{k}\right) \in W_{\text {hel }}$ such that

$a_{h}\left[\left(\boldsymbol{u}_{h}^{k} ; \underline{\sim}_{h}^{k}\right),\left(\boldsymbol{v}_{h} ; \boldsymbol{v}_{h}\right)\right]+k b_{h}\left[\left(\underline{\boldsymbol{u}}_{h}^{k} ; \underline{\underline{\boldsymbol{u}}}_{h}^{k}\right),\left(\underline{\boldsymbol{v}}_{h} ; \underline{\sim}_{h}^{\boldsymbol{v}}\right)\right]=\ell_{h}\left[\left(\boldsymbol{v}_{h} ; \boldsymbol{x}_{h}\right)\right]+f_{h}\left[\left(\boldsymbol{v}_{h} ; \boldsymbol{v}_{h}\right)\right]$

$\forall\left(\boldsymbol{v}_{h} ; \boldsymbol{v}_{h}\right) \in W_{h e l}, \quad k$ constant $>0$,

where we have set (compare with (2.1) and (2.4)):

$$
\begin{aligned}
& \left.\begin{array}{r}
a_{h}\left[\left(\boldsymbol{u}_{h} ; \boldsymbol{u}_{h}\right),\left(\boldsymbol{v}_{h} ; \boldsymbol{v}_{h}\right)\right]=\sum_{K \in \mathcal{T}_{h}} \sum_{\ell=1}^{L} \omega_{\ell, K}\left\{{ }^{T}\left[\boldsymbol{U}_{h}\right][\boldsymbol{A}]\left[\boldsymbol{V}_{h}\right]\right\}\left(b_{\ell, K}\right) \\
+\sum_{\underset{\sim}{K} \in \mathcal{I}_{h}} \sum_{\ell=1}^{L} \omega_{\ell, K}\left\{{ }^{T}\left[\boldsymbol{U}_{h}\right][\boldsymbol{A}]\left[\boldsymbol{V}_{h}\right]\right\}\left(b_{\ell, K}\right)
\end{array}\right\} \\
& b_{h}\left[\left(\left(\underline{\boldsymbol{u}}_{h} ; \underline{\underline{\boldsymbol{u}}}_{h}\right),\left(\underline{\boldsymbol{v}}_{h} ; \underline{\underline{\boldsymbol{v}}}_{h}\right)\right]=\sum_{\underline{K} \in \underline{\mathcal{I}}_{h}} \sum_{\ell=1}^{L^{\prime}} \omega_{\ell, K^{\prime}}\left\{{ }^{T}\left[\underline{\boldsymbol{U}}_{h} \underline{\boldsymbol{U}}_{h}\right][\underline{\boldsymbol{C}}]\left[\underline{\boldsymbol{V}}_{h} \underline{\boldsymbol{V}}_{h}\right]\right\}\left(b_{\ell, \underline{K}}\right) .\right.
\end{aligned}
$$

The linear forms are defined by (compare with (2.5)):

$$
\left.\begin{array}{r}
\ell_{h}\left[\left(\boldsymbol{v}_{h} ; \boldsymbol{v}_{h}\right)\right]=\sum_{K \in \mathcal{T}_{h}} \sum_{\ell=1}^{L} \omega_{\ell, K}\left\{{ }^{T}[\boldsymbol{P}]\left[\boldsymbol{V}_{h}\right]\right\}\left(b_{\ell, K}\right)+\sum_{\underset{\sim}{K} \in \mathcal{T}_{h}} \sum_{\ell=1}^{L} \omega_{\ell, K}\left\{{ }^{T}[\boldsymbol{P}]\left[\boldsymbol{V}_{h}\right]\right\}\left(b_{\ell, K}\right) \\
\quad+\sum_{K^{\prime} \in G_{1}} \sum_{\ell=1}^{L^{\prime}} \omega_{\ell, K^{\prime}}\left\{{ }^{T}\left[\boldsymbol{L}_{s}\right]\left[\boldsymbol{V}_{h}\right]\right\}\left(b_{\ell, K^{\prime}}\right)+\sum_{\underset{\sim}{K^{\prime} \in G_{1}}} \sum_{\ell=1}^{L^{\prime}}{\underset{\sim}{\ell, K_{\sim}^{\prime}}}_{\sim}\left\{{ }^{T}\left[\boldsymbol{L}_{s}\right]\left[\boldsymbol{V}_{h}\right]\right\}\left(b_{\ell, K_{\sim}^{\prime}}\right)
\end{array}\right\}
$$

where $G_{1}$ and $G_{1}$ denote the sets of the sides of triangles which are located upon $\gamma_{1}$ and ${\underset{\sim}{1}}_{1}$. Moreover (compare with (4.2)):

$$
f_{h}\left[\left(\boldsymbol{v}_{h} ; \boldsymbol{v}_{h}\right)\right]=\sum_{K^{\prime} \in G} \sum_{\ell=1}^{L^{\prime}} \omega_{\ell, K^{\prime}}\left\{{ }^{T}[\boldsymbol{N}]\left[\boldsymbol{V}_{h}\right]\right\}\left(b_{\ell, K^{\prime}}\right)+\sum_{\underset{\sim}{K^{\prime} \in G} \in} \sum_{\ell=1}^{L^{\prime}} \omega_{\ell, K_{\sim}^{\prime}}\left\{{ }^{T}[\boldsymbol{N}]\left[\boldsymbol{V}_{h}\right]\right\}\left(b_{\ell, K_{\sim}^{\prime}}\right)
$$

where $G$ and $G$ denote again the sets of the sides of triangles located on $\gamma$ and $\underset{\sim}{\gamma}$.

\subsection{Abstract error estimate}

Theorem 5.2.1 : Let us consider a family of discrete problems (5.3) for which the bilinear forms $a_{h}[.,]+.k b_{h}[.,$.$] are W_{\text {hel }}$-elliptic, uniformly with respect to $h$, i.e., there exists a constant $\beta>0$, independent of $h$, such that :

$a_{h}\left[\left(\boldsymbol{v}_{h} ; \boldsymbol{v}_{h}\right),\left(\boldsymbol{v}_{h} ; \boldsymbol{v}_{h}\right)\right]+k b_{h}\left[\left(\underline{\boldsymbol{v}}_{h} ;{\underset{\sim}{\boldsymbol{v}}}_{h}\right),\left(\underline{\boldsymbol{v}}_{h} ;{\underset{\sim}{\boldsymbol{v}}}_{h}\right)\right] \geq \beta\left\|\left(\boldsymbol{v}_{h} ; \boldsymbol{v}_{h}\right)\right\|_{E}^{2}, \quad \forall\left(\boldsymbol{v}_{h} ; \boldsymbol{v}_{h}\right) \in W_{h e l}$. 
Then, there exists a constant $C$, independent of $h$, such that

$$
\begin{aligned}
& \left\|\left(\boldsymbol{u}^{k} ;{\underset{\sim}{u}}^{k}\right)-\left(\boldsymbol{u}_{h}^{k} ; \underset{\sim}{\boldsymbol{u}_{h}^{k}}\right)\right\|_{E} \leq C_{\left(\boldsymbol{v}_{h} ; \boldsymbol{\chi}_{h}\right) \in W_{h e l}}\left\{\left\|\left(\boldsymbol{u}^{k} ;{\underset{\boldsymbol{u}}{ }}^{k}\right)-\left(\boldsymbol{v}_{h} ; \boldsymbol{v}_{h}\right)\right\|_{E}\right. \\
& +\sup _{\left(\boldsymbol{w}_{h} ; \boldsymbol{w}_{h}\right) \in W_{h e l}}\left\{\frac{\left|a\left[\left(\boldsymbol{v}_{h} ; \boldsymbol{v}_{h}\right),\left(\boldsymbol{w}_{h} ; \boldsymbol{w}_{h}\right)\right]-a_{h}\left[\left(\boldsymbol{v}_{h} ; \boldsymbol{v}_{h}\right),\left(\boldsymbol{w}_{h} ; \boldsymbol{w}_{h}\right)\right]\right|}{\left\|\left(\boldsymbol{w}_{h} ; \boldsymbol{w}_{h}\right)\right\|_{E}}\right. \\
& \left.\left.+k \frac{\left|b\left[\left(\underline{\boldsymbol{v}}_{h} ; \underline{\sim}_{h}\right),\left(\underline{\boldsymbol{w}}_{h} ; \underline{\sim}_{h}\right)\right]-b_{h}\left[\left(\underline{\boldsymbol{v}}_{h} ; \underline{\underline{\boldsymbol{v}}}_{h}\right),\left(\underline{\boldsymbol{w}}_{h} ; \underline{\sim}_{h}\right)\right]\right|}{\left\|\left(\boldsymbol{w}_{h} ; \boldsymbol{w}_{h}\right)\right\|_{E}}\right\}\right\} \\
& +C \sup _{\left(\boldsymbol{w}_{h} ; \boldsymbol{w}_{h}\right) \in W_{h e l}} \frac{\left|a\left[\left(\boldsymbol{u}^{k} ; \underline{\boldsymbol{u}}^{k}\right),\left(\boldsymbol{w}_{h} ; \boldsymbol{w}_{h}\right)\right]+k b\left[\left(\underline{\boldsymbol{u}}^{k} ; \underline{\sim}^{k}\right),\left(\underline{\boldsymbol{w}}_{h} ;{\underset{\sim}{\boldsymbol{w}}}_{h}\right)\right]-\ell_{h}\left[\left(\boldsymbol{w}_{h} ; \boldsymbol{w}_{h}\right)\right]-f_{h}\left[\left(\boldsymbol{w}_{h} ; \boldsymbol{w}_{h}\right)\right]\right|}{\left\|\left(\boldsymbol{w}_{h} ; \boldsymbol{w}_{h}\right)\right\|_{E}}
\end{aligned}
$$

where $\left(\boldsymbol{u}^{k} ;{\underset{\sim}{\boldsymbol{u}^{k}}}^{k}\right)\left(\right.$ resp. $\left.\left(\boldsymbol{u}_{h}^{k} ; \boldsymbol{u}_{h}^{k}\right)\right)$ denotes the solution of the continuous problem (Part 1, (3.10)) (resp. of the discrete problem (5.3)).

Proof : The assumption of $W_{h e l}$-ellipticity involves the existence and uniqueness of a solution $\left(\boldsymbol{u}_{h}^{k} ;{\underset{\sim}{\sim}}_{h}^{k}\right)$ for the discrete problem (5.3). Then let $\left(\boldsymbol{v}_{h} ; \boldsymbol{v}_{h}\right)$ be any element of the space $W_{h e l}$; we can write :

$$
\begin{aligned}
& \beta\left\|\left(\boldsymbol{u}_{h}^{k} ;{\underset{\sim}{u}}_{h}^{k}\right)-\left(\boldsymbol{v}_{h} ; \boldsymbol{x}_{h}\right)\right\|_{E}^{2} \leq a_{h}\left[\left(\boldsymbol{u}_{h}^{k} ;{\underset{\sim}{h}}_{h}^{k}\right)-\left(\boldsymbol{v}_{h} ; \boldsymbol{v}_{h}\right),\left(\boldsymbol{u}_{h}^{k} ;{\underset{\sim}{h}}_{h}^{k}\right)-\left(\boldsymbol{v}_{h} ; \boldsymbol{v}_{h}\right)\right] \\
& +k b_{h}\left[\left(\underline{\boldsymbol{u}}_{h}^{k} ; \underline{\underline{\boldsymbol{u}}}_{h}^{k}\right)-\left(\underline{\boldsymbol{v}}_{h} ; \underline{\sim}_{h}^{\boldsymbol{v}}\right),\left(\underline{\boldsymbol{u}}_{h}^{k} ; \underline{\underline{\boldsymbol{u}}}_{h}^{k}\right)-\left(\underline{\boldsymbol{v}}_{h} ; \underline{\sim}_{h}^{\boldsymbol{v}}\right)\right] \\
& =a\left[\left(\boldsymbol{u}^{k} ;{\underset{\sim}{u}}^{k}\right)-\left(\boldsymbol{v}_{h} ; \boldsymbol{v}_{h}\right),\left(\boldsymbol{u}_{h}^{k} ;{\underset{\sim}{h}}_{h}^{k}\right)-\left(\boldsymbol{v}_{h} ; \boldsymbol{v}_{h}\right)\right] \\
& +k b\left[\left(\underline{\boldsymbol{u}}^{k} ; \underline{\underline{\boldsymbol{u}}}^{k}\right)-\left(\underline{\boldsymbol{v}}_{h} ; \underline{\underline{\boldsymbol{v}}}_{h}\right),\left(\underline{\boldsymbol{u}}_{h}^{k} ; \underline{\sim}_{h}^{k}\right)-\left(\underline{\boldsymbol{v}}_{h} ; \underline{\sim}_{h}^{\boldsymbol{v}}\right)\right] \\
& +a\left[\left(\boldsymbol{v}_{h} ; \boldsymbol{v}_{h}\right),\left(\boldsymbol{u}_{h}^{k} ; \boldsymbol{u}_{h}^{k}\right)-\left(\boldsymbol{v}_{h} ; \boldsymbol{v}_{h}\right)\right]-a_{h}\left[\left(\boldsymbol{v}_{h} ; \boldsymbol{v}_{h}\right),\left(\boldsymbol{u}_{h}^{k} ; \boldsymbol{u}_{h}^{k}\right)-\left(\boldsymbol{v}_{h} ; \boldsymbol{v}_{h}\right)\right]
\end{aligned}
$$

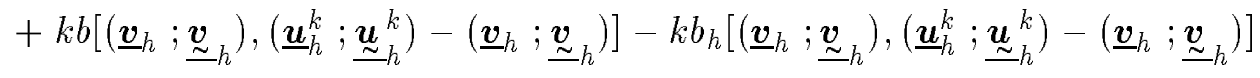

$$
\begin{aligned}
& -a\left[\left(\boldsymbol{u}^{k} ; \underline{\sim}^{k}\right),\left(\boldsymbol{u}_{h}^{k} ; \underline{\sim}_{h}^{k}\right)-\left(\boldsymbol{v}_{h} ; \boldsymbol{v}_{h}\right)\right]-k b\left[\left(\underline{\boldsymbol{u}}^{k} ; \underline{\underline{\boldsymbol{u}}}^{k}\right),\left(\underline{\boldsymbol{u}}_{h}^{k} ;{\underset{\underline{\boldsymbol{u}}}{h}}_{h}^{k}\right)-\left(\underline{\boldsymbol{v}}_{h} ; \underline{\sim}_{h}\right)\right] \\
& +\ell_{h}\left[\left(\boldsymbol{u}_{h}^{k} ; \boldsymbol{u}_{h}^{k}\right)-\left(\boldsymbol{v}_{h} ; \boldsymbol{v}_{h}\right)\right]+f_{h}\left[\left(\boldsymbol{u}_{h}^{k} ;{\underset{\sim}{\sim}}_{h}^{k}\right)-\left(\boldsymbol{v}_{h} ; \boldsymbol{v}_{h}\right)\right]
\end{aligned}
$$


so that with the continuity property (4.6) we obtain :

$$
\begin{aligned}
& \beta\left\|\left(\boldsymbol{u}_{h}^{k} ;{\underset{\sim}{h}}_{h}^{k}\right)-\left(\boldsymbol{v}_{h} ; \boldsymbol{v}_{h}\right)\right\|_{E} \leq M \|\left(\boldsymbol{u}^{k} ;{\left.\underset{\sim}{\boldsymbol{u}^{k}}\right)}^{k}\left(\boldsymbol{v}_{h} ; \boldsymbol{v}_{h}\right) \|_{E}\right. \\
& +\sup _{\left(\boldsymbol{w}_{h} ; \boldsymbol{w}_{h}\right) \in W_{h e l}}\left\{\frac{\left|a\left[\left(\boldsymbol{v}_{h} ; \boldsymbol{v}_{h}\right),\left(\boldsymbol{w}_{h} ; \boldsymbol{w}_{h}\right)\right]-a_{h}\left[\left(\boldsymbol{v}_{h} ; \boldsymbol{v}_{h}\right),\left(\boldsymbol{w}_{h} ; \boldsymbol{w}_{h}\right)\right]\right|}{\left\|\left(\boldsymbol{w}_{h} ; \boldsymbol{w}_{h}\right)\right\|_{E}}\right. \\
& \left.+k \frac{\left|b\left[\left(\underline{\boldsymbol{v}}_{h} ; \underline{\boldsymbol{v}}_{h}\right),\left(\underline{\boldsymbol{w}}_{h} ; \underline{\sim}_{h}^{\boldsymbol{w}}\right)\right]-b_{h}\left[\left(\underline{\boldsymbol{v}}_{h} ; \underline{\underline{v}}_{h}\right),\left(\underline{\boldsymbol{w}}_{h} ; \underline{\sim}_{h}\right)\right]\right|}{\left\|\left(\boldsymbol{w}_{h} ; \underline{\boldsymbol{w}}_{h}\right)\right\|_{E}}\right\} \\
& +\sup _{\left(\boldsymbol{w}_{h} ; \boldsymbol{w}_{h}\right) \in W_{h e l}} \frac{\left|a\left[\left(\boldsymbol{u}^{k} ; \underline{\sim}^{k}\right),\left(\boldsymbol{w}_{h} ; \boldsymbol{w}_{h}\right)\right]+k b\left[\left(\underline{\boldsymbol{u}}^{k} ; \underline{\sim}^{k}\right),\left(\underline{\boldsymbol{w}}_{h} ; \underline{\sim}_{h}\right)\right]-\ell_{h}\left[\left(\boldsymbol{w}_{h} ; \boldsymbol{w}_{h}\right)\right]-f_{h}\left[\left(\boldsymbol{w}_{h} ; \boldsymbol{w}_{h}\right)\right]\right|}{\left\|\left(\boldsymbol{w}_{h} ; \boldsymbol{w}_{h}\right)\right\|_{E}} .
\end{aligned}
$$

To conclude, it remains to use the triangular inegality and to take the minimum with respect to $\left(\boldsymbol{v}_{h} ; \boldsymbol{v}_{h}\right) \in W_{h e l}$.

In the estimate (5.8), in addition to the usual approximation theory term $\inf \|\left(\boldsymbol{u}^{k} ;{\underset{\sim}{\boldsymbol{u}}}^{k}\right)-$ $\left(\boldsymbol{v}_{h} ; \boldsymbol{v}_{h}\right) \|$, we find two additional terms which measure the consistency error between the bilinear forms $a[.,$.$] and a_{h}[.,],. b[.,$.$] and b_{h}[.,$.$] ; they take into account$ the error due to the numerical integration. Finally, the last term combines the error due to both approximations, i.e., nonconforming approximation along the hinge and use of the numerical integration techniques.

\section{$5.3 \quad$ Uniform ellipticity}

The uniform $W_{h e l}$-ellipticity is based on the local error estimate theorems given by Bernadou (1996, p. 53-61) for a triangle $K$ and by Cubier (1994, p. 76-87) for a triangle side $K^{\prime}$. These theorems give a general result of error estimate ; they specify criteria on the choice of numerical integration schemes in order to obtain the same order of asymptotic error estimate than for exact integration.

Theorem 5.3.1 : Let $\mathcal{T}_{h}$ and $\mathcal{T}_{h}$ be regular families of triangulations of the domains $\Omega$ and $\underset{\sim}{\Omega}$ satisfying properties (3.1) to (3.3). Let $\left(K, P_{K}, \Sigma_{K}\right)$ and $\left(\underset{\sim}{K}, P_{K}, \Sigma_{K}\right)$ be two almost affine families of finite elements associated with the Argyris triangle. Thus we have

$$
P_{K}=P_{5}(K), \forall K \in \mathcal{T}_{h} \text { and } P_{K}=P_{5}(\underset{\sim}{K}), \forall \underset{\sim}{K} \in \mathcal{I}_{h}
$$

Moreover, assume that the integration scheme on the reference triangle $\hat{K}$ satisfies the following conditions :

i) the integration nodes $\hat{b}_{\ell} \in \overline{\hat{K}}, \forall \ell=1, . ., L$;

ii) $\hat{E}(\hat{\varphi})=0, \forall \hat{\varphi} \in P_{8}(\hat{K})$.

Likewise, the integration scheme on the reference segment $\hat{K}^{\prime}$ verifies

iii) the integration nodes $\hat{b}_{\ell}^{\prime} \in \overline{\hat{K}^{\prime}}, \forall \ell=1, . ., L^{\prime}$; 
iv) $\hat{E}^{\prime}(\hat{\varphi})=0, \forall \hat{\varphi} \in P_{8}\left(\hat{K}^{\prime}\right)$.

Then, for any given $A_{I J} \in W^{1, \infty}(\Omega), A_{I J} \in W^{1, \infty}(\underset{\sim}{\Omega}), I, J=1, . ., 12$ and $\underline{C}_{I J} \in$ $W^{1, \infty}(\omega)$,

$I, J=1, . ., 24$, there exist constants $\beta>0$ and $h_{1}>0$, independent of $h$, such that for all $\left.h \in] 0, h_{1}\right]$, we have

$a_{h}\left[\left(\boldsymbol{v}_{h} ; \boldsymbol{v}_{h}\right),\left(\boldsymbol{v}_{h} ; \boldsymbol{v}_{h}\right)\right]+k b_{h}\left[\left(\underline{\boldsymbol{v}}_{h} ;{\underset{\sim}{\boldsymbol{v}}}_{h}\right),\left(\underline{\boldsymbol{v}}_{h} ;{\underset{\sim}{\boldsymbol{v}}}_{h}\right)\right] \geq \beta\left\|\left(\boldsymbol{v}_{h} ; \boldsymbol{v}_{h}\right)\right\|_{E}^{2}, \quad \forall\left(\boldsymbol{v}_{h} ; \boldsymbol{v}_{h}\right) \in W_{h e l}$.

Proof : For any $\left(\boldsymbol{v}_{h} ; \boldsymbol{v}_{h}\right) \in W_{h e l} \subset V_{h} \times V_{h}$, the inclusions (3.4) allow us to write

$$
\left.\begin{array}{rl} 
& a_{h}\left[\left(\boldsymbol{v}_{h} ; \boldsymbol{v}_{h}\right),\left(\boldsymbol{v}_{h} ; \boldsymbol{v}_{h}\right)\right]+k b_{h}\left[\left(\underline{\boldsymbol{v}}_{h} ; \underline{\sim}_{h}\right),\left(\underline{\boldsymbol{v}}_{h} ; \underline{\sim}_{h}\right)\right] \\
= & a\left[\left(\boldsymbol{v}_{h} ; \boldsymbol{v}_{h}\right),\left(\boldsymbol{v}_{h} ; \boldsymbol{v}_{h}\right)\right]+k b\left[\left(\underline{\boldsymbol{v}}_{h} ; \underline{\boldsymbol{v}}_{h}\right),\left(\underline{\boldsymbol{v}}_{h} ; \underline{\underline{v}}_{h}\right)\right] \\
& +a_{h}\left[\left(\boldsymbol{v}_{h} ; \underline{\boldsymbol{v}}_{h}\right),\left(\boldsymbol{v}_{h} ; \boldsymbol{v}_{h}\right)\right]-a\left[\left(\boldsymbol{v}_{h} ; \underline{\boldsymbol{v}}_{h}\right),\left(\boldsymbol{v}_{h} ; \underline{\boldsymbol{v}}_{h}\right)\right] \\
+ & k b_{h}\left[\left(\underline{\boldsymbol{v}}_{h} ; \underline{\underline{v}}_{h}\right),\left(\underline{\boldsymbol{v}}_{h} ; \underline{\sim}_{h}\right)\right]-k b\left[\left(\underline{\boldsymbol{v}}_{h} ; \underline{\underline{v}}_{h}\right),\left(\underline{\boldsymbol{v}}_{h} ; \underline{\sim}_{h}\right)\right],
\end{array}\right\}
$$

where $a[.,$.$] and b[.,$.$] are defined by relations (2.1) and (2.4). According to the proof$ of Lemma 4.2.2, there exists a constant $\alpha>0$, independent of $h$, such that for any $\left(\boldsymbol{v}_{h} ; \boldsymbol{v}_{h}\right) \in W_{h e l}$

$$
a\left[\left(\boldsymbol{v}_{h} ; \boldsymbol{v}_{h}\right),\left(\boldsymbol{v}_{h} ; \boldsymbol{v}_{h}\right)\right]+k b\left[\left(\underline{\boldsymbol{v}}_{h} ;{\underset{\sim}{\boldsymbol{v}}}_{h}\right),\left(\underline{\boldsymbol{v}}_{h} ;{\underset{\sim}{\boldsymbol{v}}}_{h}\right)\right] \geq \alpha\left\|\left(\boldsymbol{v}_{h} ; \boldsymbol{v}_{h}\right)\right\|_{E}^{2} .
$$

This result and the assumptions of Theorem 5.3.1 allow us to apply Theorem 1.3.3 of Bernadou (1996, p. 57) to the different types of terms which occur in the second hand member of the following inequality

$$
\begin{gathered}
\left|a\left[\left(\boldsymbol{v}_{h} ; \boldsymbol{v}_{h}\right),\left(\boldsymbol{v}_{h} ; \boldsymbol{v}_{h}\right)\right]-a_{h}\left[\left(\boldsymbol{v}_{h} ; \boldsymbol{v}_{h}\right),\left(\boldsymbol{v}_{h} ; \boldsymbol{v}_{h}\right)\right]\right| \\
\leq \sum_{K \in \mathcal{T}_{h}} \sum_{I, J=1}^{12}\left|E_{K}\left(\boldsymbol{A}_{I J} \boldsymbol{V}_{h I} \boldsymbol{V}_{h J}\right)\right|+\sum_{\underset{J}{K} \in \mathcal{I}_{h}} \sum_{I, J=1}^{12}\left|E_{\underset{\sim}{K}}\left(\boldsymbol{A}_{I J} \boldsymbol{V}_{h I} \boldsymbol{V}_{h J}\right)\right| .
\end{gathered}
$$

Thus, there exists a constant $C>0$, independent of $h$, which can change from an inequality to the next and such that

$$
\begin{gathered}
\left|a\left[\left(\boldsymbol{v}_{h} ; \boldsymbol{v}_{h}\right),\left(\boldsymbol{v}_{h} ; \boldsymbol{v}_{h}\right)\right]-a_{h}\left[\left(\boldsymbol{v}_{h} ; \boldsymbol{v}_{h}\right),\left(\boldsymbol{v}_{h} ; \boldsymbol{v}_{h}\right)\right]\right| \\
\leq C\left(\sum_{K \in \mathcal{T}_{h}} h_{K}\left(\sum_{I, J=1}^{12}\left\|\boldsymbol{A}_{I J}\right\|_{1, \infty, \Omega}\right)\left\|\boldsymbol{v}_{h}\right\|_{V(K)}^{2}+\sum_{I_{\sim} \in \mathcal{T}_{h}} h_{K}\left(\sum_{I, J=1}^{12}\left\|\boldsymbol{A}_{I J}\right\|_{1, \infty, \Omega}\right)\left\|\boldsymbol{v}_{h}\right\|_{V(K)}^{2}\right) \\
\leq C h \sup \left\{\sum_{I, J=1}^{12}\left\|\boldsymbol{A}_{I J}\right\|_{1, \infty, \Omega}, \sum_{I, J=1}^{12}\left\|\boldsymbol{A}_{I J}\right\|_{1, \infty, \Omega}\right\}\left\|\left(\boldsymbol{v}_{h} ; \boldsymbol{v}_{h}\right)\right\|_{E}^{2} \\
\leq C h\left\|\left(\boldsymbol{v}_{h} ; \boldsymbol{v}_{h}\right)\right\|_{E}^{2} .
\end{gathered}
$$


Now, we have to estimate the term $b\left[\left(\underline{\boldsymbol{v}}_{h} ;{\underset{\sim}{\boldsymbol{v}}}_{h}\right),\left(\underline{\boldsymbol{v}}_{h} ;{\underset{\sim}{\boldsymbol{v}}}_{h}\right)\right]-b_{h}\left[\left(\underline{\boldsymbol{v}}_{h} ; \underline{\sim}_{h}^{\boldsymbol{v}}\right),\left(\underline{\boldsymbol{v}}_{h} ; \underline{\sim}_{h}\right)\right]$.

By using definition (5.2) of the error functional, we obtain

$$
\left|b\left[\left(\underline{\boldsymbol{v}}_{h} ; \underline{\sim}_{h}^{\boldsymbol{v}}\right),\left(\underline{\boldsymbol{v}}_{h} ; \underline{\underline{\boldsymbol{v}}}_{h}\right)\right]-b_{h}\left[\left(\underline{\boldsymbol{v}}_{h} ; \underline{\underline{\boldsymbol{v}}}_{h}\right),\left(\underline{\boldsymbol{v}}_{h} ; \underline{\sim}_{h}^{\boldsymbol{v}}\right)\right]\right| \leq \sum_{\underline{K} \in \underline{\mathcal{T}}_{h}} \sum_{I, J=1}^{24}\left|E_{\underline{K}}^{\prime}\left(\underline{\boldsymbol{C}}_{I J}\left[\underline{\boldsymbol{V}}_{h} \underline{\boldsymbol{V}}_{h}\right]_{I}\left[\underline{\boldsymbol{V}}_{h} \underline{\boldsymbol{V}}_{h}\right]_{J}\right)\right| .
$$

If we denote

$$
\begin{aligned}
& I_{1}=\{1, . ., 12\} \times\{1, . ., 12\} ; I_{2}=\{13, . ., 24\} \times\{13, . ., 24\} ; \\
& I_{3}=\{1, . ., 12\} \times\{13, . ., 24\} ; I_{4}=\{13, . ., 24\} \times\{1, . ., 12\},
\end{aligned}
$$

then, we have the relation

$$
\left.\begin{array}{l}
\sum_{\underline{K} \in \mathcal{I}_{h}} \sum_{I, J=1}^{24}\left|E_{\underline{K}}^{\prime}\left(\underline{\boldsymbol{C}}_{I J}\left[\underline{\boldsymbol{V}}_{h} \underline{\boldsymbol{V}}_{h}\right]_{I}\left[\underline{\boldsymbol{V}}_{h} \underline{\boldsymbol{V}}_{h}\right]_{J}\right)\right|=\sum_{\underline{K} \in \underline{\mathcal{I}}_{h}} \sum_{I, J \in I_{1}}\left|E_{\underline{K}}^{\prime}\left(\underline{\boldsymbol{C}}_{I J}\left[\underline{\boldsymbol{V}}_{h}\right]_{I}\left[\underline{\boldsymbol{V}}_{h}\right]_{J}\right)\right| \\
+\sum_{\underline{K} \in \mathcal{I}_{h}} \sum_{I, J \in I_{2}}\left|E_{\underline{K}}^{\prime}\left(\underline{\boldsymbol{C}}_{I J}\left[\underline{\boldsymbol{V}}_{h}\right]_{I}\left[\underline{\boldsymbol{V}}_{h}\right]_{J}\right)\right|+\sum_{\underline{K} \in \underline{\mathcal{I}}_{h}} \sum_{I, J \in I_{3} \cup I_{4}}\left|E_{\underline{K}}^{\prime}\left(\underline{\boldsymbol{C}}_{I J}\left[\underline{\boldsymbol{V}}_{h}\right]_{I}\left[\underline{\boldsymbol{V}}_{h}\right]_{J}\right)\right|
\end{array}\right\}
$$

With the hypotheses made in the statement of the theorem, we can apply to these one dimensional integration terms of the relation (5.13) the same kind of technique and we obtain (see Cubier (1994, p.83) for details)

$$
\begin{aligned}
& \sum_{\underline{K} \in \mathcal{I}_{h}} \sum_{I, J \in I_{1}}\left|E_{\underline{K}}^{\prime}\left(\underline{\boldsymbol{C}}_{I J}\left[\underline{\boldsymbol{V}}_{h}\right]_{I}\left[\underline{\boldsymbol{V}}_{h}\right]_{J}\right)\right| \leq C h \sum_{\underline{K} \in \mathcal{I}_{h}}\left(\sum_{I, J \in I_{1}}\left\|\underline{\boldsymbol{C}}_{I J}\right\|_{1, \infty, \underline{K}}\right)\left\|\boldsymbol{v}_{h}\right\|_{V(K)}^{2}, \\
& \sum_{\underline{K} \in \mathcal{I}_{h}} \sum_{I, J \in I_{2}}\left|E_{\underline{K}}^{\prime}\left(\underline{\boldsymbol{C}}_{I J}\left[\underline{\boldsymbol{V}}_{h}\right]_{I}\left[\underline{\boldsymbol{V}}_{h}\right]_{J}\right)\right| \leq C h \sum_{\underline{K} \in \mathcal{I}_{h}}\left(\sum_{I, J \in I_{2}}\left\|\underline{\boldsymbol{C}}_{I J}\right\|_{1, \infty, \underline{K}}\right)\left\|\boldsymbol{v}_{h}\right\|_{V(\underset{\sim}{K})}^{2}, \\
& \sum_{\underline{K} \in \mathcal{I}_{h}} \sum_{I, J \in I_{3} \cup I_{4}}\left|E_{\underline{K}}^{\prime}\left(\underline{\boldsymbol{C}}_{I J}\left[\underline{\boldsymbol{V}}_{h}\right]_{I}\left[\underline{\boldsymbol{V}}_{h}\right]_{J}\right)\right| \leq C h \sum_{\underline{K} \in \underline{\mathcal{I}}_{h}}\left(\sum_{I, J \in I_{3} \cup I_{4}}\left\|\underline{\boldsymbol{C}}_{I J}\right\|_{1, \infty, \underline{K}}\right)\left\|\boldsymbol{v}_{h}\right\|_{V(K)}\left\|\boldsymbol{v}_{h}\right\|_{V(\underline{N})},
\end{aligned}
$$

so that the substitution of these inequalities into relation (5.13) proves the existence of a constant $C$, independent of $h$, such that

$$
\left.\begin{array}{c}
\left|b\left[\left(\underline{\boldsymbol{v}}_{h} ; \underline{\underline{\boldsymbol{v}}}_{h}\right),\left(\underline{\boldsymbol{v}}_{h} ;{\underset{\sim}{\boldsymbol{v}}}_{h}\right)\right]-b_{h}\left[\left(\underline{\boldsymbol{v}}_{h} ;{\underset{\sim}{\boldsymbol{v}}}_{h}\right),\left(\underline{\boldsymbol{v}}_{h} ;{\underset{\sim}{\boldsymbol{v}}}_{h}\right)\right]\right| \\
\leq C h\left(\sum_{I, J=1}^{24}\left\|\underline{\boldsymbol{C}}_{I J}\right\|_{1, \infty, \omega}\right)\left\|\left(\boldsymbol{v}_{h} ; \boldsymbol{v}_{h}\right)\right\|_{E}^{2} \leq C h\left\|\left(\boldsymbol{v}_{h} ; \boldsymbol{v}_{h}\right)\right\|_{E}^{2} \cdot
\end{array}\right\}
$$

By substituting relations (5.11), (5.12), (5.14) into relation (5.10), we get

$$
a_{h}\left[\left(\boldsymbol{v}_{h} ; \boldsymbol{v}_{h}\right),\left(\boldsymbol{v}_{h} ; \boldsymbol{v}_{h}\right)\right]+k b_{h}\left[\left(\underline{\boldsymbol{v}}_{h} ;{\underset{\sim}{\boldsymbol{v}}}_{h}\right),\left(\underline{\boldsymbol{v}}_{h} ;{\underset{\underline{v}}{\boldsymbol{v}}}_{h}\right)\right] \geq(\alpha-C h)\left\|\left(\boldsymbol{v}_{h} ; \boldsymbol{v}_{h}\right)\right\|_{E}^{2}
$$

and it suffices to take $\beta=\frac{\alpha}{2}$ and $h_{1}=\frac{\alpha}{2 C}$ to obtain the expected estimate (5.9).

Remark 5.3.1 : Numerical integration schemes exact for polynomial of degree eight can be found in Dunavant (1985, p. 1140) for the triangle and in Zienkiewicz-Taylor (1989, p.173) for an interval. 


\subsection{Asymptotic error estimate}

Now, we are able to evaluate the different terms of the abstract error estimate (5.8) and to derive an asymptotic error estimate $\left\|(\boldsymbol{u} ; \boldsymbol{u})-\left(\boldsymbol{u}_{h} ; \boldsymbol{u}_{h}\right)\right\|$ between the solution $(\boldsymbol{u} ; \boldsymbol{u})$ of the continuous problem (Part 1, (3.10)) and the solutions of the discrete problems (5.3). Before giving the asymptotic error estimate theorem, let us specify some notations :

$$
\begin{gathered}
\|(\boldsymbol{p} ; \boldsymbol{p})\|_{\left(W^{4, q}(\Omega)\right)^{3} \times\left(W^{4, q}(\Omega)\right)^{3}}=\left\{\sum_{i=1}^{3}\left\|p^{i}\right\|_{4, q, \Omega}^{q}+\sum_{i=1}^{3}\left\|{\underset{\sim}{p}}_{\sim}^{i}\right\|_{4, q, \Omega}^{q}\right\}^{1 / q} \\
\left\|\left(\boldsymbol{L}_{s}, \boldsymbol{L}_{s}\right)\right\|_{\left(W^{5, s}\left(\gamma_{1}\right)\right)^{12} \times\left(W^{5, s}\left(\mathcal{\sim}_{1}\right)\right)^{12}}=\left\{\sum_{I=1}^{12}\left\|\boldsymbol{L}_{s I}\right\|_{5, s, \gamma_{1}}^{s}+\sum_{I=1}^{12}\left\|\boldsymbol{L}_{s I}\right\|_{5, s, \mathcal{\sim}_{1}}^{s}\right\}^{1 / s},
\end{gathered}
$$

where $q, s$ are two integer numbers $\geq 1$.

Theorem 5.4.1 : Let $\mathcal{T}_{h}$ and $\mathcal{T}_{h}$ be two regular families of triangulations of the domains $\Omega$ and $\underset{\sim}{\Omega}$ satisfying the properties (3.1) to (3.3). Let $\left(K, P_{K}, \Sigma_{K}\right)$ and $\left(\underset{\sim}{K}, P_{K}, \Sigma_{K}\right)$ be two almost affine families of finite elements associated with the Argyris triangle. Moreover, we assume that the numerical integration scheme on the reference triangle $\hat{K}$ satisfies the following conditions :

i) the integration nodes $\hat{b}_{\ell} \in \overline{\hat{K}}, \forall \ell=1, . ., L$;

ii) $\hat{E}(\hat{\varphi})=0, \forall \hat{\varphi} \in P_{8}(\hat{K})$.

Likewise, the numerical integration scheme on the reference interval $\hat{K}^{\prime}$ verifies

iii) the integration nodes $\hat{b}_{\ell}^{\prime} \in \overline{\hat{K}^{\prime}}, \forall \ell=1, . ., L^{\prime}$;

iv) $\hat{E}^{\prime}(\hat{\varphi})=0, \quad \forall \hat{\varphi} \in P_{8}\left(\hat{K}^{\prime}\right)$.

Assume that

v) the solution $\left(\boldsymbol{u}^{k} ; \underline{\boldsymbol{u}}^{k}\right) \in W_{\text {el }}$ of the continuous problem (Part 1, (3.10)) belongs to the space $K(\Omega) \times \underset{\sim}{K}(\Omega)=\left(H^{5}(\Omega)\right)^{2} \times H^{6}(\Omega) \times\left(H^{5}(\underset{\sim}{\Omega})\right)^{2} \times H^{6}(\underset{\sim}{\Omega})$,

vi) $\boldsymbol{A}_{I J} \in W^{4, \infty}(\Omega), \boldsymbol{A}_{I J} \in W^{4, \infty}(\underset{\sim}{\Omega})$ for $I, J=1, . ., 12$;

vii) $\underline{\boldsymbol{C}}_{I J} \in W^{4, \infty}(\omega)$ for $I, J=1, . ., 24$;

viii) $p^{i} \in W^{4, q}(\Omega), p_{\sim}^{i} \in W^{4, q}(\underset{\sim}{\Omega})$ for $i=1, . ., 3$;

ix) $N^{i} \in W^{5, s}(\gamma), \quad N_{\sim}^{i} \in W^{5, s}(\underset{\sim}{\gamma})$ for $i=1, . ., 3$;

x) $\boldsymbol{L}_{s I} \in W^{5, s}\left(\gamma_{1}\right), \quad \boldsymbol{L}_{s I} \in W^{5, s}\left({\underset{\sim}{1}}_{1}\right)$ for $I=1, . ., 12$, 
where $q, s$ are integer numbers $\geq 2$. Then, there exist constants $C>0$ and $h_{1}>0$, independent of $h$, such that for any $\left.h \in] 0, h_{1}\right]$, we have :

$$
\begin{aligned}
& \left\|\left(\boldsymbol{u}^{k} ;{\underset{\sim}{u}}^{k}\right)-\left(\boldsymbol{u}_{h}^{k} ;{\underset{\sim}{h}}_{h}^{k}\right)\right\|_{E} \leq C h^{4}\left\{\left\|\left(\boldsymbol{u}^{k} ; \underline{\sim}^{k}\right)\right\|_{K(\Omega) \times \underset{\sim}{K}(\Omega)}+\|(\boldsymbol{p} ; \boldsymbol{p})\|_{\left(W^{4, q}(\Omega)\right)^{3} \times\left(W^{4, q}(\Omega)\right)^{3}}\right. \\
& \left.+h^{1 / 2}\left[\|(\boldsymbol{N} ; \boldsymbol{N})\|_{\left(W^{5, s}(\gamma)\right)^{3} \times\left(W^{5, s}(\underset{\sim}{\gamma})\right)^{3}}+\left\|\left(\boldsymbol{L}_{s}, \boldsymbol{L}_{s}\right)\right\|_{\left(W^{5, s}\left(\gamma_{1}\right)\right)^{12} \times\left(W^{5, s}\left(\mathcal{\sim}_{1}\right)\right)^{12}}\right]\right\}
\end{aligned}
$$

where $\left(\boldsymbol{u}_{h}^{k} ; \boldsymbol{u}_{\sim}^{k}\right)$ is the solution of the discrete problem (5.3).

Proof The conditions for applying Theorem 5.3.1 are satisfied. Hence, the condition of the uniform $W_{h e l}$-ellipticity is verified and it is possible to apply Theorem 5.2.1. Therefore, we are going to evaluate the different terms of the second hand member of the inequality (5.8). The proof takes five steps.

Step 1: Estimate of $\inf _{\left(\boldsymbol{v}_{h} ; \boldsymbol{v}_{h}\right) \in W_{h e l}}\left\|\left(\boldsymbol{u}^{k} ; \underset{\sim}{\boldsymbol{u}^{k}}\right)-\left(\boldsymbol{v}_{h} ; \boldsymbol{v}_{h}\right)\right\|_{E}$

Let $\Pi_{h}$ be the $W_{h e l}$ interpolation operator on the space $W_{e l}$. We define

$$
\Pi_{h}(\boldsymbol{v} ; \boldsymbol{v})=\left(\pi_{h} \boldsymbol{v}, \pi_{h} \boldsymbol{v}\right)
$$

where $\pi_{h}$ and $\pi_{h}$ are the associated interpolation operators on $V_{h}$ and $V_{h}$. Then, we obtain

(Ciarlet (1978 p. 124))

$$
\left.\begin{array}{rl}
\inf _{\left(\boldsymbol{v}_{h} ; \boldsymbol{v}_{h}\right) \in W_{h e l}}\left\|\left(\boldsymbol{u}^{k} ;{\underset{\sim}{\boldsymbol{u}}}^{k}\right)-\left(\boldsymbol{v}_{h} ; \boldsymbol{v}_{h}\right)\right\|_{E} & \leq\left\|\left(\boldsymbol{u}^{k} ;{\underset{\sim}{u}}^{k}\right)-\Pi_{h}\left(\boldsymbol{u}^{k} ;{\underset{\sim}{u}}^{k}\right)\right\|_{E} \\
& \leq C h^{4}\left\|\left(\boldsymbol{u}^{k} ;{\underset{\sim}{u}}^{k}\right)\right\|_{K(\Omega) \times \underset{\sim}{K(\Omega)}} .
\end{array}\right\}
$$

Step 2: Estimate of $\sup _{\left(\boldsymbol{w}_{h} ; \boldsymbol{w}_{h}\right) \in W_{h e l}} \frac{\left|a\left[\Pi_{h}\left(\boldsymbol{u}^{k} ; \underline{\boldsymbol{u}}^{k}\right),\left(\boldsymbol{w}_{h} ; \boldsymbol{w}_{h}\right)\right]-a_{h}\left[\Pi_{h}\left(\boldsymbol{u}^{k} ; \boldsymbol{u}^{k}\right),\left(\boldsymbol{w}_{h} ; \boldsymbol{w}_{h}\right)\right]\right|}{\left\|\left(\boldsymbol{w}_{h} ; \boldsymbol{w}_{h}\right)\right\|_{E}}$

By using relations (2.1) and (5.1) :

$$
\begin{aligned}
& \left|a\left[\Pi_{h}\left(\boldsymbol{u}^{k} ;{\underset{\sim}{u}}^{k}\right),\left(\boldsymbol{w}_{h} ; \boldsymbol{w}_{h}\right)\right]-a_{h}\left[\Pi_{h}\left(\boldsymbol{u}^{k} ;{\underset{\sim}{\boldsymbol{u}^{k}}}^{k}\right),\left(\boldsymbol{w}_{h} ; \boldsymbol{w}_{h}\right)\right]\right| \\
& \left.\leq \sum_{K \in \mathcal{T}_{h}} \sum_{I, J=1}^{12}\left|E_{K}\left(\boldsymbol{A}_{I J}\left[\pi_{h} \boldsymbol{U}^{k}\right]_{I} \boldsymbol{W}_{J}\right)\right|+\sum_{\underset{\sim}{K} \in \mathcal{L}_{h}} \sum_{I, J=1}^{12}\left|E_{\boldsymbol{N}}\left(\boldsymbol{A}_{I J}\left[\pi_{h} \boldsymbol{U}_{\sim}^{k}\right]_{I} \boldsymbol{W}_{J}\right)\right| \cdot\right\}
\end{aligned}
$$

We restrict our attention to the first term of the second hand member of inequality (5.17). The hypotheses of Bernadou (1996, Theorem 1.3.3, p. 57) are verified. Thus, we obtain the existence of a constant $C>0$, independent of $h$, such that

$$
\begin{gathered}
\sum_{K \in \mathcal{T}_{h}} \sum_{I, J=1}^{12}\left|E_{K}\left(\boldsymbol{A}_{I J}\left[\pi_{h} \boldsymbol{U}^{k}\right]_{I} \boldsymbol{W}_{J}\right)\right| \\
\leq C \sum_{K \in \mathcal{T}_{h}} h_{K}^{4}\left(\sum_{I, J=1}^{12}\left\|\boldsymbol{A}_{I J}\right\|_{4, \infty, K}\right)\left(\left\|\pi_{h} u_{1}^{k}\right\|_{5, K}^{2}+\left\|\pi_{h} u_{2}^{k}\right\|_{5, K}^{2}+\left\|\pi_{h} u_{3}^{k}\right\|_{6, K}^{2}\right)^{1 / 2}\left\|\boldsymbol{w}_{h}\right\|_{V(K)}
\end{gathered}
$$


where

$$
\begin{gathered}
\pi_{h} \boldsymbol{u}=\left(\pi_{h} u_{1}, \quad\left(\pi_{h} u_{1}\right)_{, 1}, \quad\left(\pi_{h} u_{1}\right)_{, 2}, \pi_{h} u_{2}, \quad\left(\pi_{h} u_{2}\right)_{, 1}, \quad\left(\pi_{h} u_{2}\right)_{, 2},\right. \\
\left.\pi_{h} u_{3}, \quad\left(\pi_{h} u_{3}\right)_{, 1}, \quad\left(\pi_{h} u_{3}\right)_{, 2}, \quad\left(\pi_{h} u_{3}\right)_{, 11}, \quad\left(\pi_{h} u_{3}\right)_{, 12}, \quad\left(\pi_{h} u_{3}\right)_{, 22}\right)
\end{gathered}
$$

The interpolation operator $\pi_{h 1}$ leaves the space $P_{5}(K)$ invariant, and we obtain

$$
\left\|\pi_{h} u_{i}\right\|_{5, K} \leq\left\|u_{i}\right\|_{5, K}+\left\|u_{i}-\pi_{h} u_{i}\right\|_{5, K} \leq C\left\|u_{i}\right\|_{5, K}, \quad i=1,2,3 .
$$

Thus,

$$
\sum_{K \in \mathcal{T}_{h}} \sum_{I, J=1}^{12}\left|E_{K}\left(\boldsymbol{A}_{I J}\left[\pi_{h} \boldsymbol{U}^{k}\right]_{I}[\boldsymbol{W}]_{h J}\right)\right| \leq C \max _{K \in \mathcal{T}_{h}}\left(h_{K}\right)^{4}\left(\sum_{I, J=1}^{12}\left\|\boldsymbol{A}_{I J}\right\|_{4, \infty, \Omega}\right)\left\|\boldsymbol{u}^{k}\right\|_{K(\Omega)}\left\|\boldsymbol{w}_{h}\right\|_{V(\Omega)}
$$

Similarly for the shell $\mathcal{S}$, we could prove

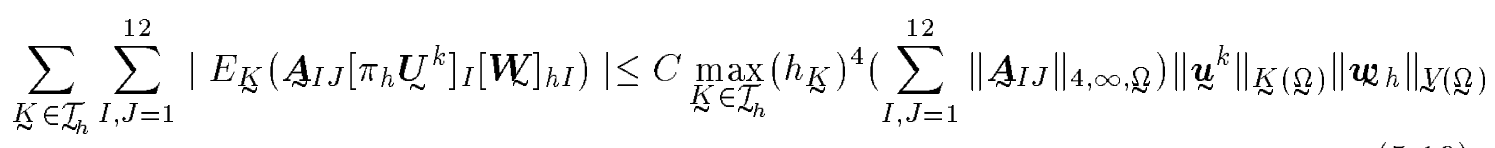

By combining inequalities (5.18), (5.19) and definition (3.2), we obtain

$$
\begin{gathered}
\left|a\left[\Pi_{h}\left(\boldsymbol{u}^{k} ;{\underset{\sim}{\sim}}^{k}\right),\left(\boldsymbol{w}_{h} ; \boldsymbol{w}_{h}\right)\right]-a_{h}\left[\Pi_{h}\left(\boldsymbol{u}^{k} ;{\underset{\sim}{\sim}}^{k}\right),\left(\boldsymbol{w}_{h} ; \boldsymbol{w}_{h}\right)\right]\right| \\
\leq C h^{4} \sup \left\{\sum_{I, J=1}^{12}\left\|\boldsymbol{A}_{I J}\right\|_{4, \infty, \Omega}, \sum_{I, J=1}^{12}\left\|\boldsymbol{A}_{I J}\right\|_{4, \infty, \Omega}\right\}\left\{\left\|\boldsymbol{u}^{k}\right\|_{K(\Omega)}\left\|\boldsymbol{w}_{h}\right\|_{V(\Omega)}+\left\|{\underset{\sim}{\sim}}^{k}\right\|_{I_{(}(\Omega)}\left\|\boldsymbol{w}_{h}\right\|_{\nu(\Omega)}\right\}
\end{gathered}
$$

so that

$$
\left.\begin{array}{l}
\sup _{\left(\boldsymbol{w}_{h} ; \boldsymbol{w}_{h}\right) \in W_{h e l}} \frac{\left|a\left[\Pi_{h}\left(\boldsymbol{u}^{k} ; \boldsymbol{u}^{k}\right),\left(\boldsymbol{w}_{h} ; \boldsymbol{w}_{h}\right)\right]-a_{h}\left[\Pi_{h}\left(\boldsymbol{u}^{k} ;{\underset{\sim}{*}}^{k}\right),\left(\boldsymbol{w}_{h} ; \boldsymbol{w}_{h}\right)\right]\right|}{\left\|\left(\boldsymbol{w}_{h} ; \boldsymbol{w}_{h}\right)\right\|_{E}} \\
\leq C h^{4} \sup \left\{\sum_{I, J=1}^{12}\left\|\boldsymbol{A}_{I J}\right\|_{4, \infty, \Omega}, \sum_{I, J=1}^{12}\left\|\boldsymbol{A}_{I J}\right\|_{4, \infty, \Omega}\right\} \|\left(\boldsymbol{u}^{k} ; \underset{\sim}{\left.\boldsymbol{u}^{k}\right) \|_{K(\Omega) \times K}(\Omega)}\right.
\end{array}\right\}
$$

Step 3: Estimate of $\sup _{\left(\boldsymbol{w}_{h} ; \boldsymbol{w}_{h}\right) \in W_{h e l}} \frac{\left|b\left[\Pi_{h}\left(\underline{\boldsymbol{u}}^{k} ; \underline{\underline{\boldsymbol{u}}}^{k}\right),\left(\underline{\boldsymbol{w}}_{h} ; \underline{\sim}_{h}\right)\right]-b_{h}\left[\Pi_{h}\left(\underline{\boldsymbol{w}}^{k} ; \underline{\sim}^{k}\right),\left(\underline{\boldsymbol{w}}_{h} ; \underline{\sim}_{h}\right)\right]\right|}{\left\|\left(\boldsymbol{w}_{h} ; \boldsymbol{w}_{h}\right)\right\|_{E}}$

The restriction of an Argyris triangle to one of its side is a $P_{5}$-one-dimensional finite element, so that we define the interpolating function:

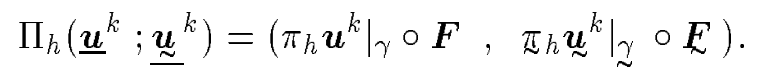

By using the matrix expressions (2.4) and (5.5) of the bilinear forms $b[.,$.$] and b_{h}[.,$. , a similar one-dimensional study to the previous ones gives (for details, see Cubier 
(1994, Theorem 5.2.4, p. 83))

$$
\begin{aligned}
& \left|b\left[\Pi_{h}\left(\underline{\boldsymbol{u}}^{k} ; \underline{\boldsymbol{u}}^{k}\right),\left(\underline{\boldsymbol{w}}_{h} ; \underline{\sim}_{h}\right)\right]-b_{h}\left[\Pi_{h}\left(\underline{\boldsymbol{u}}^{k} ; \underline{\boldsymbol{u}}^{k}\right),\left(\underline{\boldsymbol{w}}_{h} ; \underline{\sim}_{h}\right)\right]\right| \\
& \leq C h^{4}\left(\sum_{I, J=1}^{24}\left\|\underline{\boldsymbol{C}}_{I J}\right\|_{4, \infty, \underline{K}}\right)\left[\left\|\boldsymbol{u}^{k}\right\|_{K(\Omega)}\left\|\boldsymbol{w}_{h}\right\|_{V(\Omega)}+\left\|\underline{\boldsymbol{u}}^{k}\right\|_{\underset{\sim}{K(\Omega)}}\left\|\boldsymbol{w}_{h}\right\|_{\nu(\Omega)}\right]
\end{aligned}
$$

so that, we obtain

$$
\left.\begin{array}{c}
\frac{\left|b\left[\Pi_{h}\left(\underline{\boldsymbol{u}}^{k} ; \underline{\boldsymbol{u}}^{k}\right),\left(\underline{\boldsymbol{w}}_{h} ;{\underset{\sim}{\boldsymbol{w}} h}_{h}\right)\right]-b_{h}\left[\Pi_{h}\left(\underline{\boldsymbol{u}}^{k} ; \underline{\boldsymbol{u}}^{k}\right),\left(\underline{\boldsymbol{w}}_{h} ; \underline{\sim}_{h}\right)\right]\right|}{\left\|\left(\boldsymbol{w}_{h} ; \boldsymbol{w}_{h}\right)\right\|_{E}} \\
\leq C h^{4}\left(\sum_{I, J=1}^{24}\left\|\underline{\boldsymbol{C}}_{I J}\right\|_{4, \infty, \omega}\right)\left\|\left(\boldsymbol{u}^{k} ;{\underset{\sim}{\boldsymbol{u}}}^{k}\right)\right\|_{K(\Omega) \times \underset{\sim}{K}(\Omega)} .
\end{array}\right\}
$$

Step 4: Estimate of

$$
\sup _{\left(\boldsymbol{w}_{h} ; \boldsymbol{w}_{h}\right) \in W_{h e l}} \frac{\left|a\left[\left(\boldsymbol{u}^{k} ;{\underset{\sim}{\boldsymbol{u}}}^{k}\right),\left(\boldsymbol{w}_{h} ; \boldsymbol{w}_{h}\right)\right]+k b\left[\left(\underline{\boldsymbol{u}}^{k} ;{\underset{\sim}{\boldsymbol{u}}}^{k}\right),\left(\underline{\boldsymbol{w}}_{h} ; \underline{\sim}_{h}^{\boldsymbol{w}}\right)\right]-\ell_{h}\left[\left(\boldsymbol{w}_{h} ; \boldsymbol{w}_{h}\right)\right]-f_{h}\left[\left(\boldsymbol{w}_{h} ; \boldsymbol{w}_{h}\right)\right]\right|}{\left\|\left(\boldsymbol{w}_{h} ; \boldsymbol{w}_{h}\right)\right\|_{E}}
$$

By using relation (4.7), we obtain the new estimate :

$$
\begin{aligned}
& \sup _{\left(\boldsymbol{w}_{h} ; \boldsymbol{w}_{h}\right) \in W_{h e l}} \frac{\left|a\left[\left(\boldsymbol{u}^{k} ; \underline{\sim}^{k}\right),\left(\boldsymbol{w}_{h} ; \boldsymbol{w}_{h}\right)\right]+k b\left[\left(\underline{\underline{u}}^{k} ; \underline{\sim}^{k}\right),\left(\underline{\boldsymbol{w}}_{h} ; \underline{\sim}_{h}\right)\right]-\ell_{h}\left[\left(\boldsymbol{w}_{h} ; \boldsymbol{w}_{h}\right)\right]-f_{h}\left[\left(\boldsymbol{w}_{h} ; \boldsymbol{w}_{h}\right)\right]\right|}{\left\|\left(\boldsymbol{w}_{h} ; \boldsymbol{w}_{h}\right)\right\|_{E}} \\
& \leq \sup _{\left(\boldsymbol{w}_{h} ; \boldsymbol{w}_{h}\right) \in W_{h e l}} \frac{\left|\ell\left[\left(\boldsymbol{w}_{h} ; \boldsymbol{w}_{h}\right)\right]-\ell_{h}\left[\left(\boldsymbol{w}_{h} ; \boldsymbol{w}_{h}\right)\right]\right|}{\left\|\left(\boldsymbol{w}_{h} ; \boldsymbol{w}_{h}\right)\right\|_{E}}+\sup _{\left(\boldsymbol{w}_{h} ; \boldsymbol{w}_{h}\right) \in W_{h e l}} \frac{\left|f\left[\left(\boldsymbol{w}_{h} ; \boldsymbol{w}_{h}\right)\right]-f_{h}\left[\left(\boldsymbol{w}_{h} ; \boldsymbol{w}_{h}\right)\right]\right|}{\left\|\left(\boldsymbol{w}_{h} ; \boldsymbol{w}_{h}\right)\right\|_{E}}
\end{aligned}
$$

In this inequality, we find the term $\left|f\left[\left(\boldsymbol{w}_{h} ; \boldsymbol{w}_{h}\right)\right]-f_{h}\left[\left(\boldsymbol{w}_{h} ; \boldsymbol{w}_{h}\right)\right]\right|$ which combines the errors due to the nonconformity of the finite element method and to the use of numerical integration. Thus, it remains to study the following estimates

$$
\text { - Estimate of } \sup _{\left(\boldsymbol{w}_{h} ; \boldsymbol{w}_{h}\right) \in W_{h e l}} \frac{\left|\ell\left[\left(\boldsymbol{w}_{h} ; \boldsymbol{w}_{h}\right)\right]-\ell_{h}\left[\left(\boldsymbol{w}_{h} ; \boldsymbol{w}_{h}\right)\right]\right|}{\left\|\left(\boldsymbol{w}_{h} ; \boldsymbol{w}_{h}\right)\right\|_{E}}
$$

We can rewrite the linear forms $\ell[$.$] and \ell_{h}[$.$] by using the matrix decompositions$ introduced in Section 2 ; thus we obtain

$$
\left.\begin{array}{rl}
\mid \ell\left[\left(\boldsymbol{w}_{h} ; \boldsymbol{w}_{h}\right)\right] & -\ell_{h}\left[\left(\boldsymbol{w}_{h} ; \boldsymbol{w}_{h}\right)\right]\left|\leq \sum_{K \in \mathcal{T}_{h}} \sum_{I=1}^{12}\right| E_{K}\left([\boldsymbol{P}]_{I}\left[\boldsymbol{W}_{h}\right]_{I}\right)\left|+\sum_{\underset{\sim}{K} \in \mathcal{T}_{h}} \sum_{I=1}^{12}\right| E_{K^{K}}\left([\boldsymbol{P}]_{I}\left[\boldsymbol{W}_{h}\right]_{I}\right) \mid \\
& +\sum_{K^{\prime} \in G_{1}} \sum_{I=1}^{12}\left|E_{K^{\prime}}^{\prime}\left(\left[\boldsymbol{L}_{s}\right]_{I}\left[\boldsymbol{W}_{h}\right]_{I}\right)\right|+\sum_{\mathcal{N}^{\prime} \in G_{1}} \sum_{I=1}^{12}\left|E_{K^{\prime}}^{\prime}\left(\left[\boldsymbol{L}_{s}\right]_{I}\left[\boldsymbol{W}_{h}\right]_{I}\right)\right|
\end{array}\right\}
$$


where the sets $G_{1}$ and $G_{1}$ are defined in (5.6). The first two terms of the second hand member of (5.22) correspond to body force resultants ; the last two terms correspond to surface load resultants. In order to estimate these terms, we can use Bernadou (1996, Theorem 1.3.2, p. 54) and their one dimensional counterparts by Cubier (1994, Theorem 5.2.3, p.79). That leads to :

$$
\begin{aligned}
& \left|\ell\left[\left(\boldsymbol{w}_{h} ; \boldsymbol{w}_{h}\right)\right]-\ell_{h}\left[\left(\boldsymbol{w}_{h} ; \boldsymbol{w}_{h}\right)\right]\right| \leq C \sum_{K \in \mathcal{T}_{h}} h_{K}^{4}(\operatorname{mes}(K))^{1 / 2-1 / q}\left(\sum_{I=1}^{12}\left\|\boldsymbol{P}_{I}\right\|_{4, q, K}^{q}\right)^{1 / q}\left\|\boldsymbol{w}_{h}\right\|_{V(K)} \\
& +C \sum_{\underset{\sim}{K} \in \mathcal{T}_{h}} h_{\underset{\sim}{K}}^{4}(\operatorname{mes}(\underset{\sim}{K}))^{1 / 2-1 / q}\left(\sum_{I=1}^{12}\left\|\boldsymbol{P}_{I}\right\|_{4, q, K}^{q}\right)^{1 / q}\left\|\boldsymbol{w}_{h}\right\|_{\nu(K)} \\
& +C \sum_{K^{\prime} \in G_{1}} h_{K^{*}}^{9 / 2}\left(\operatorname{mes}\left(K^{\prime}\right)\right)^{1 / 2-1 / s}\left(\sum_{I=1}^{12}\left\|\boldsymbol{L}_{s I}\right\|_{5, s, K^{\prime}}^{s}\right)^{1 / s}\left\|\boldsymbol{w}_{h}\right\|_{V\left(K^{*}\right)} \\
& +C \sum_{\mathcal{\sim}^{\prime} \in G_{1}}{\underset{\sim}{h^{*}}}_{\sim}^{9 / 2}\left(\operatorname{mes}\left(\underset{\sim}{K^{\prime}}\right)\right)^{1 / 2-1 / s}\left(\sum_{I=1}^{12}\left\|\boldsymbol{L}_{s I}\right\|_{5, s, K_{\sim}^{\prime}}^{s}\right)^{1 / s}\left\|\boldsymbol{w}_{h}\right\|_{\nu\left(\underset{\sim}{K^{*}}\right)},
\end{aligned}
$$

where $K^{*}$ (resp. ${\underset{\sim}{K}}^{*}$ ) denote the triangles belonging to $\mathcal{T}_{h}$ (resp. $\mathcal{I}_{h}$ ) which count the sides $K^{\prime}$ (resp. $\underset{\sim}{K}$ ) located on $\gamma_{1}$ (resp. $\underset{\sim}{\gamma_{1}}$ ) among their own sides. Figure 3 summarizes these notations.

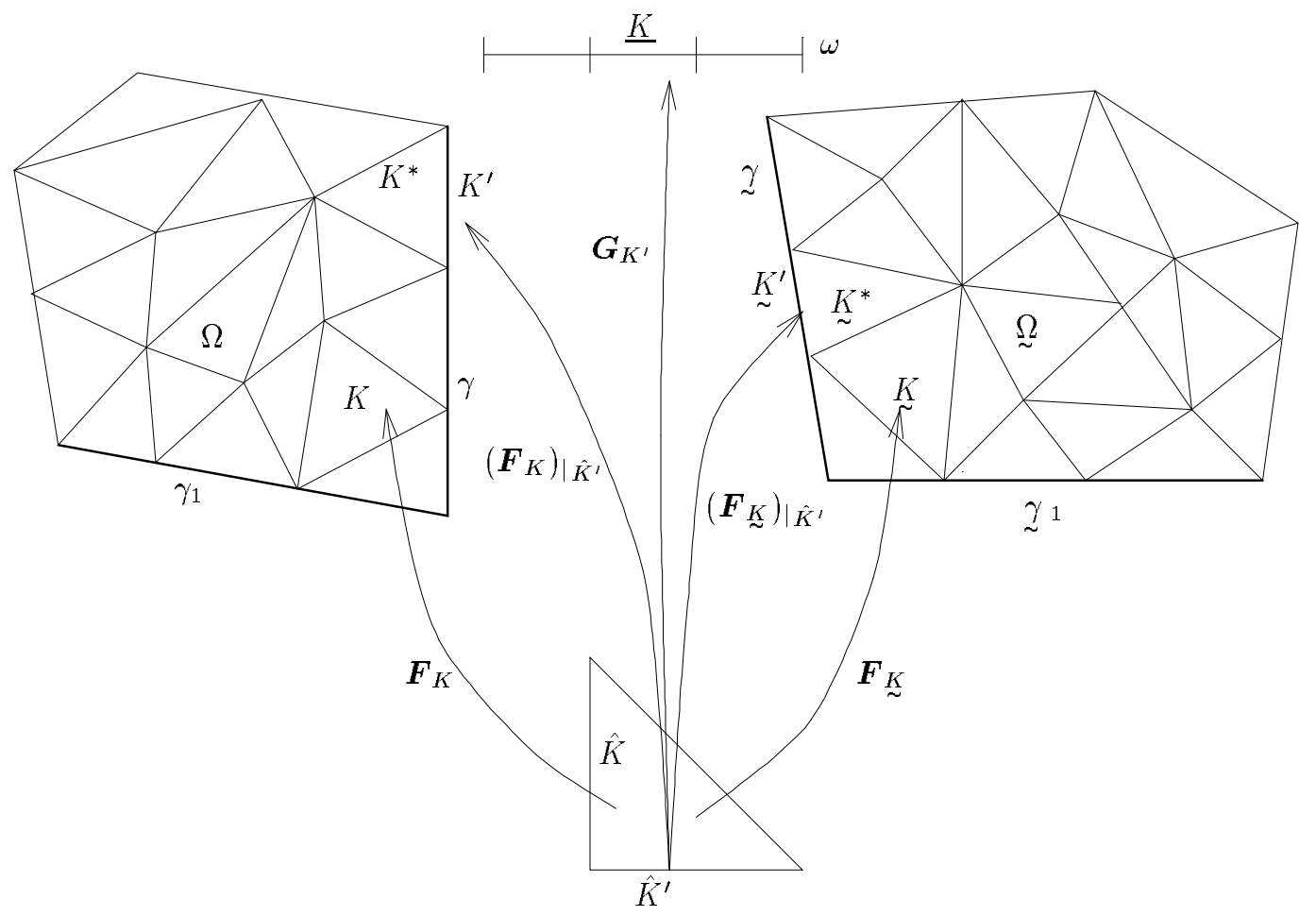

Fig. 3: Some notations 
From definitions (2.6) of vectors $\boldsymbol{P}$ and $\boldsymbol{P}$, we have

$$
\sum_{I=1}^{12}\left\|\boldsymbol{P}_{I}\right\|_{4, q, K}^{q}=\sum_{i=1}^{3}\left\|p^{i}\right\|_{4, q, K}^{q} \quad \text { and } \quad \sum_{I=1}^{12}\left\|\boldsymbol{P}_{I}\right\|_{4, q, K}^{q}=\sum_{i=1}^{3}\left\|p^{i}\right\|_{4, q, \underset{\sim}{q}}^{q} .
$$

Then, we use the inequality

$$
\sum_{K}\left|a_{K} b_{K} c_{K}\right| \leq\left(\sum_{K}\left|a_{K}\right|^{\alpha}\right)^{1 / \alpha}\left(\sum_{K}\left|b_{K}\right|^{\beta}\right)^{1 / \beta}\left(\sum_{K}\left|c_{K}\right|^{\gamma}\right)^{1 / \gamma}
$$

which is valid for any real numbers $\alpha, \beta, \gamma \geq 1$ satisfying $\frac{1}{\alpha}+\frac{1}{\beta}+\frac{1}{\gamma}=1$. Here, we take $\frac{1}{\alpha}=\frac{1}{2}-\frac{1}{q}, \quad \beta=q$ et $\gamma=2$ for body force terms and $\frac{1}{\alpha}=\frac{1}{2}-\frac{1}{s} ; \beta=s$ et $\gamma=2$ for surface load terms, for any $q \geq 2$ and $s \geq 2$. Hence

$$
\begin{gathered}
\sup _{\left(\boldsymbol{w}_{h} ; \boldsymbol{w}_{h}\right) \in W_{h e l}} \frac{\left|\ell\left[\left(\boldsymbol{w}_{h} ; \boldsymbol{w}_{h}\right)\right]-\ell_{h}\left[\left(\boldsymbol{w}_{h} ; \boldsymbol{w}_{h}\right)\right]\right|}{\left\|\left(\boldsymbol{w}_{h} ; \boldsymbol{w}_{h}\right)\right\|_{E}} \leq C h^{4}\left\{\mid(\boldsymbol{p} ; \boldsymbol{p}) \|_{\left(W^{4, q}(\Omega)\right)^{3} \times\left(W^{4, q}(\Omega)\right)^{3}}\right. \\
\left.+h^{1 / 2}\left\|\left(\boldsymbol{L}_{s}, \underline{\sim}_{s}\right)\right\|_{\left(W^{5, s}\left(\gamma_{1}\right)\right)^{12} \times\left(W^{5, s}\left(\sim_{1}^{1}\right)\right)^{12}}\right\}
\end{gathered}
$$

- Estimate of $\sup _{\left(\boldsymbol{w}_{h} ; \boldsymbol{w}_{h}\right) \in W_{h e l}} \frac{\left|f\left[\left(\boldsymbol{w}_{h} ; \boldsymbol{w}_{h}\right)\right]-f_{h}\left[\left(\boldsymbol{w}_{h} ; \boldsymbol{w}_{h}\right)\right]\right|}{\left\|\left(\boldsymbol{w}_{h} ; \boldsymbol{w}_{h}\right)\right\|_{E}}$

The final result is obtained by taking into account the matrix expression of $f[$.$] and$ $f_{h}[$.$] defined by relation (5.7) ; a proof similar to the previous ones ( see Cubier$ (1994, Theorem 5.2.3, p.79)) would lead to

$\sup _{\left(\boldsymbol{w}_{h} ; \boldsymbol{w}_{h}\right) \in W_{h e l}} \frac{\left|f\left[\left(\boldsymbol{w}_{h} ; \boldsymbol{w}_{h}\right)\right]-f_{h}\left[\left(\boldsymbol{w}_{h} ; \boldsymbol{w}_{h}\right)\right]\right|}{\left\|\left(\boldsymbol{w}_{h} ; \boldsymbol{w}_{h}\right)\right\|_{E}} \leq C h^{9 / 2}\|(N ; N)\|_{\left(W^{5, s}(\gamma)\right)^{3} \times\left(W^{5, s}(\underset{\sim}{\gamma})\right)^{3}}$

Step 5 : Final estimate (5.15)

We can apply Theorem 5.2.1 and we get the estimate (5.15) by substitution of the inequalities $(5.16),(5.20),(5.21),(5.23)$ and $(5.24)$ into the abstract error estimate (5.8) written for $\left(\boldsymbol{v}_{h} ; \boldsymbol{v}_{h}\right)=\Pi_{h}\left(\boldsymbol{u}^{k} ;{\underset{\sim}{ }}^{k}\right)$.

\section{Extension to the rigid junction problem}

The rigid junction problem can be stated as follows

$$
\left.\begin{array}{l}
\text { Find }\left(\boldsymbol{u}_{h r i g} ; \boldsymbol{u}_{h r i g}\right) \in W_{h r i g} \text { such that for any }\left(\boldsymbol{v}_{h} ; \boldsymbol{v}_{h}\right) \in W_{h r i g} \\
a_{h}\left[\left(\boldsymbol{u}_{h r i g} ; \boldsymbol{u}_{h r i g}\right),\left(\boldsymbol{v}_{h} ; \boldsymbol{v}_{h}\right)\right]=\ell_{h}\left[\left(\boldsymbol{v}_{h} ; \boldsymbol{v}_{h}\right)\right]+f_{h}^{*}\left[\left(\boldsymbol{v}_{h} ; \boldsymbol{v}_{h}\right)\right]
\end{array}\right\}
$$


where the space $W_{h r i g}$, the bilinear form $a_{h}[.,$.$] and the form \ell_{h}[$.$] are respectively$ given by relations $(3.13),(5.4),(5.6)$ and, concerning the approximation along the hinge :

$$
f_{h}^{*}\left[\left(\boldsymbol{v}_{h} ; \boldsymbol{v}_{h}\right)\right]=\sum_{K^{\prime} \in G} \sum_{\ell=1}^{L^{\prime}} \omega_{\ell, K^{\prime}}\left\{{ }^{T}\left[\boldsymbol{L}_{s}\right]\left[\boldsymbol{V}_{h}\right]\right\}\left(b_{\ell, K^{\prime}}\right)+\sum_{\underset{\sim}{K^{\prime} \in G}} \sum_{\ell=1}^{L^{\prime}} \omega_{\ell, K_{\sim}^{\prime}}\left\{{ }^{T}\left[\boldsymbol{L}_{s}\right]\left[\boldsymbol{V}_{\sim}\right]\right\}\left(b_{\ell, K_{\sim}^{\prime}}\right)
$$

where $\boldsymbol{L}_{s}$ and $\boldsymbol{L}_{s}$ are defined in (2.7) and sets $G$ and $G$ are given in relation (5.7).

Theorem 6.1 (Abstract error estimate) : Let us consider a family of discrete problems (6.1). We suppose that the bilinear forms $a_{h}[.,$.$] are W_{\text {hrig-elliptic, uniformly }}$ with respect to $h$, i.e., there exists a constant $\beta>0$, independent of $h$, such that

$$
a_{h}\left[\left(\boldsymbol{v}_{h} ; \boldsymbol{v}_{h}\right),\left(\boldsymbol{v}_{h} ; \boldsymbol{x}_{h}\right)\right] \geq \beta\left\|\left(\boldsymbol{v}_{h} ; \boldsymbol{v}_{h}\right)\right\|_{E}^{2}, \quad \forall\left(\boldsymbol{v}_{h} ; \boldsymbol{v}_{h}\right) \in W_{h r i g} .
$$

Then, there exists a constant $C>0$, independent of $h$, such that

$$
\begin{aligned}
& \left\|\left(\boldsymbol{u}_{r i g} ; \boldsymbol{u}_{r i g}\right)-\left(\boldsymbol{u}_{h r i g} ; \boldsymbol{u}_{h r i g}\right)\right\|_{E} \leq C_{\left(\boldsymbol{v}_{h} ; \boldsymbol{v}_{h}\right) \in W_{h r i g}}\left\{\left\|\left(\boldsymbol{u}_{r i g} ; \boldsymbol{u}_{r i g}\right)-\left(\boldsymbol{v}_{h} ; \boldsymbol{x}_{h}\right)\right\|_{E}\right. \\
& \left.+\sup _{\left(\boldsymbol{w}_{h} ; \boldsymbol{w}_{h}\right) \in W_{h r i g}} \frac{\left|a\left[\left(\boldsymbol{v}_{h} ; \boldsymbol{v}_{h}\right),\left(\boldsymbol{w}_{h} ; \boldsymbol{w}_{h}\right)\right]-a_{h}\left[\left(\boldsymbol{v}_{h} ; \boldsymbol{w}_{h}\right),\left(\boldsymbol{w}_{h} ; \boldsymbol{w}_{h}\right)\right]\right|}{\left\|\left(\boldsymbol{w}_{h} ; \boldsymbol{w}_{h}\right)\right\|_{E}}\right\} \\
& +C \sup _{\left(\boldsymbol{w}_{h} ; \boldsymbol{w}_{h}\right) \in W_{h r i g}} \frac{\left|a\left[\left(\boldsymbol{u}_{r i g} ; \boldsymbol{u}_{r i g}\right),\left(\boldsymbol{w}_{h} ; \boldsymbol{w}_{h}\right)\right]-\ell_{h}\left[\left(\boldsymbol{w}_{h} ; \boldsymbol{w}_{h}\right)\right]-f_{h}^{*}\left[\left(\boldsymbol{w}_{h} ; \boldsymbol{w}_{h}\right)\right]\right|}{\left\|\left(\boldsymbol{w}_{h} ; \boldsymbol{w}_{h}\right)\right\|_{E}}
\end{aligned}
$$

where $\left(\boldsymbol{u}_{\text {rig }} ; \boldsymbol{u}_{\text {rig }}\right)$ and $\left(\boldsymbol{u}_{\text {hrig }} ; \boldsymbol{u}_{\text {hrig }}\right)$ denote the solutions of the continuous and discrete problems (Part 1, (3.24)) and (6.1).

Proof : The proof is similar to that of Theorem 5.2.1 for the elastic hinge problem ; it suffices to note that $b[.,]=.b_{h}[.,]=$.0 .

Theorem 6.2 (Asymptotic error estimate) : Let $\mathcal{T}_{h}$ and $\mathcal{T}_{h}$ be two regular families of triangulations of the domains $\Omega$ and $\Omega$ satisfying properties (3.1) to (3.3). Let $\left(K, P_{K}, \Sigma_{K}\right)$ and $\left(\underset{\sim}{K}, P_{K}, \Sigma_{K}\right)$ be two almost affine families of finite elements associated with the Argyris triangle. Moreover, we assume that the numerical integration scheme on the reference triangle $\hat{K}$ satisfies the following conditions :

i) the integration nodes $\hat{b}_{\ell} \in \overline{\hat{K}}, \forall \ell=1, . ., L$;

ii) $\hat{E}(\hat{\varphi})=0, \forall \hat{\varphi} \in P_{8}(\hat{K})$.

Likewise, the numerical integration scheme on the reference interval $\hat{K}^{\prime}$ verifies

iii) the integration nodes $\hat{b}_{\ell}^{\prime} \in \overline{\hat{K}^{\prime}}, \forall \ell=1, . ., L^{\prime}$;

iv) $\hat{E}^{\prime}(\hat{\varphi})=0, \quad \forall \hat{\varphi} \in P_{8}\left(\hat{K}^{\prime}\right)$. 
Assume that

v) the solution $\left(\boldsymbol{u}_{\text {rig }} ; \boldsymbol{u}_{\text {rig }}\right) \in W_{\text {rig }}$ of the continuous problem (Part 1,(3.24)) belongs to the space $K(\Omega) \times K(\Omega)=\left(H^{5}(\Omega)\right)^{2} \times H^{6}(\Omega) \times\left(H^{5}(\underset{\sim}{\Omega})\right)^{2} \times H^{6}(\underset{\sim}{\Omega}) ;$

vi) $\boldsymbol{A}_{I J} \in W^{4, \infty}(\Omega), \boldsymbol{A}_{I J} \in W^{4, \infty}(\underset{\sim}{\Omega})$ for $I, J=1, . ., 12$;

vii) $p^{i} \in W^{4, q}(\Omega), \underset{\sim}{p^{i}} \in W^{4, q}(\underset{\sim}{\Omega})$ for $i=1, . ., 3$;

viii) $\boldsymbol{L}_{s I} \in W^{5, s}\left(\gamma_{1} \cup \gamma\right), \quad \boldsymbol{L}_{s I} \in W^{5, s}\left({\underset{\sim}{1}}_{1} \cup \underset{\sim}{\gamma}\right)$ for $I=1, . ., 12$,

where $q, s$ are integer numbers $\geq 2$. Then, there exist constants $C>0$ and $h_{1}>0$, independent of $h$, such that for any $\left.h \in] 0, h_{1}\right]$ we have :

$$
\begin{gathered}
\left\|\left(\boldsymbol{u}_{\text {rig }}, \boldsymbol{u}_{\text {rig }}\right)-\left(\boldsymbol{u}_{\text {hrig }}, \boldsymbol{u}_{h r i g}\right)\right\|_{E} \leq C h^{4}\left\{\left\|\left(\boldsymbol{u}_{\text {rig }}, \boldsymbol{u}_{\text {rig }}\right)\right\|_{K(\Omega) \times \underset{\sim}{K(\Omega)}(\underset{\sim}{)})}\right. \\
\left.+\|(\boldsymbol{p} ; \boldsymbol{p})\|_{\left(W^{4, q}(\Omega)\right)^{3} \times\left(W^{4, q}(\Omega)\right)^{3}}+h^{1 / 2}\left\|\left(\boldsymbol{L}_{s}, \boldsymbol{L}_{s}\right)\right\|_{\left.\left(W^{5, s}\left(\gamma_{1} \cup \gamma\right)\right)^{12} \times\left(W^{5, s}(\underset{\sim}{\gamma} \underset{\sim}{\gamma})\right)^{12}\right]}\right\}
\end{gathered}
$$

where $\left(\boldsymbol{u}_{\text {hrig }} ; \boldsymbol{u}_{\text {hrig }}\right)$ is the solution of the discrete problems (6.1)

Proof : The uniform ellipticity arises from the equivalence between the norm $\|\cdot\|_{E}$ and the norm on $W_{\text {hrig }}$ defined by $\left\|\left(\boldsymbol{v}_{h} ; \boldsymbol{x}_{h}\right)\right\|_{W_{\text {hrig }}}=\left\{a_{h}\left[\left(\boldsymbol{v}_{h} ; \boldsymbol{v}_{h}\right),\left(\boldsymbol{v}_{h} ; \boldsymbol{v}_{h}\right)\right]\right\}^{1 / 2}$ and from Bernadou (1996, Theorem 1.3.3). Then we can obtain the aymptotic error estimate exactly in the same way than for the elastic junction problem.

\section{$7 \quad$ Numerical Results}

\subsection{Description of the example}

We consider the example given in (Part 1, Section 2.4), i.e., a structure constituted by a circular cylinder with a spherical end cap subjected to a vertical body force. The cylinder is clamped along its foundations. Figure 4 and Table 1 give the notations and the data used for this benchmark. The axisymmetry of this structure

\begin{tabular}{|c|c|c|}
\hline Dimensions & Material constants & Forces \\
\hline $\begin{array}{l}L=130.9 m \\
r=95.1 m \\
R=100 m \\
e=e=1 m \\
\theta_{0}=\frac{2 \pi}{5} \\
\delta=\frac{\pi}{10}\end{array}$ & $\begin{array}{l}E=E=10^{5} \mathrm{~N} / \mathrm{m}^{2} \\
\nu=\chi=0.33\end{array}$ & $\begin{aligned} \boldsymbol{p} & =\boldsymbol{p} \\
& =-b \boldsymbol{e}_{\mathbf{3}} \\
b & =10 \mathrm{~N} / \mathrm{m}^{2}\end{aligned}$ \\
\hline
\end{tabular}
leads to simplifications, in particular if we consider axisymmetrical loading.

Table 1 : Data of the example 


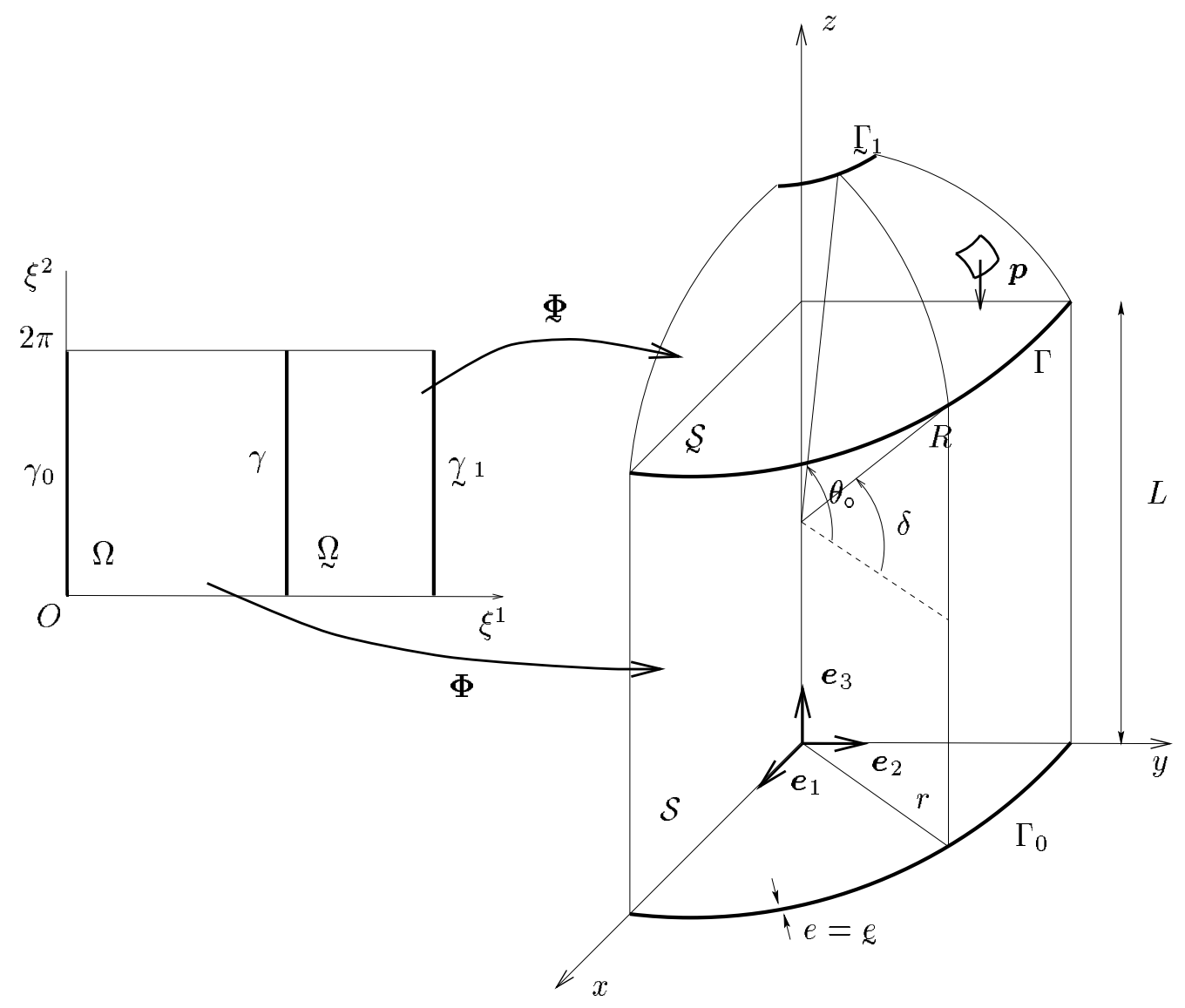

Fig. 4: Geometry of the problem

The mappings that we consider are given by :

$$
\Phi:\left\{\begin{array}{l}
x=r \cos \xi^{2} \\
y=r \sin \xi^{2} \\
z=\xi^{1}
\end{array} \quad \Phi:\left\{\begin{array}{l}
x=R \cos \left(\delta+\frac{\xi^{1}-L}{R}\right) \cos \xi^{2} \\
y=R \cos \left(\delta+\frac{\xi^{1}-L}{R}\right) \sin \xi^{2} \\
z=R \sin \left(\delta+\frac{\xi^{1}-L}{R}\right)+L-R \sin \delta
\end{array}\right.\right.
$$

Here, we consider the junction between the sphere and the cylinder ; the above mappings are such that $\Phi^{-1}(\Gamma)=\Phi^{-1}(\Gamma)=\gamma$. Thus we do not need to introduce the third mapping $\underline{\Phi}$ and the interval $\omega$ (see (2.3) and (2.4)). In this benchmark the bilinear form $b[.,$.$] is given by$

$$
b[(\boldsymbol{u} ; \boldsymbol{u}),(\boldsymbol{v} ; \boldsymbol{v})]=\int_{\gamma}\left(u_{3,1}-u_{3,1}-\frac{1}{R} u_{1}\right)\left(v_{3,1}-\underline{v}_{3,1}-\frac{1}{R} \underline{v}_{1}\right) d \gamma
$$

where $d \gamma=r^{2} d \xi^{2}($ Part $1,(2.15)$ and $(3.12))$. 


\subsection{Reference solution}

As a reference deformed configuration of the structure we use the approximated solution of the three-dimensional linearized elasticity model. The axisymmetry allow us to restrict the problem to a two-dimensional axisymmetrical elasticity problem set on a radial section of the structure. We approximate this problem by a finite element method using $P_{1}$-Lagrange finite elements. In order to have a good approximation of the deformed configuration, we have used a mesh including 17408 triangles. Figure 5 gives the result that we have obtained with the Modulef code (see Bernadou \& al. (1988)).
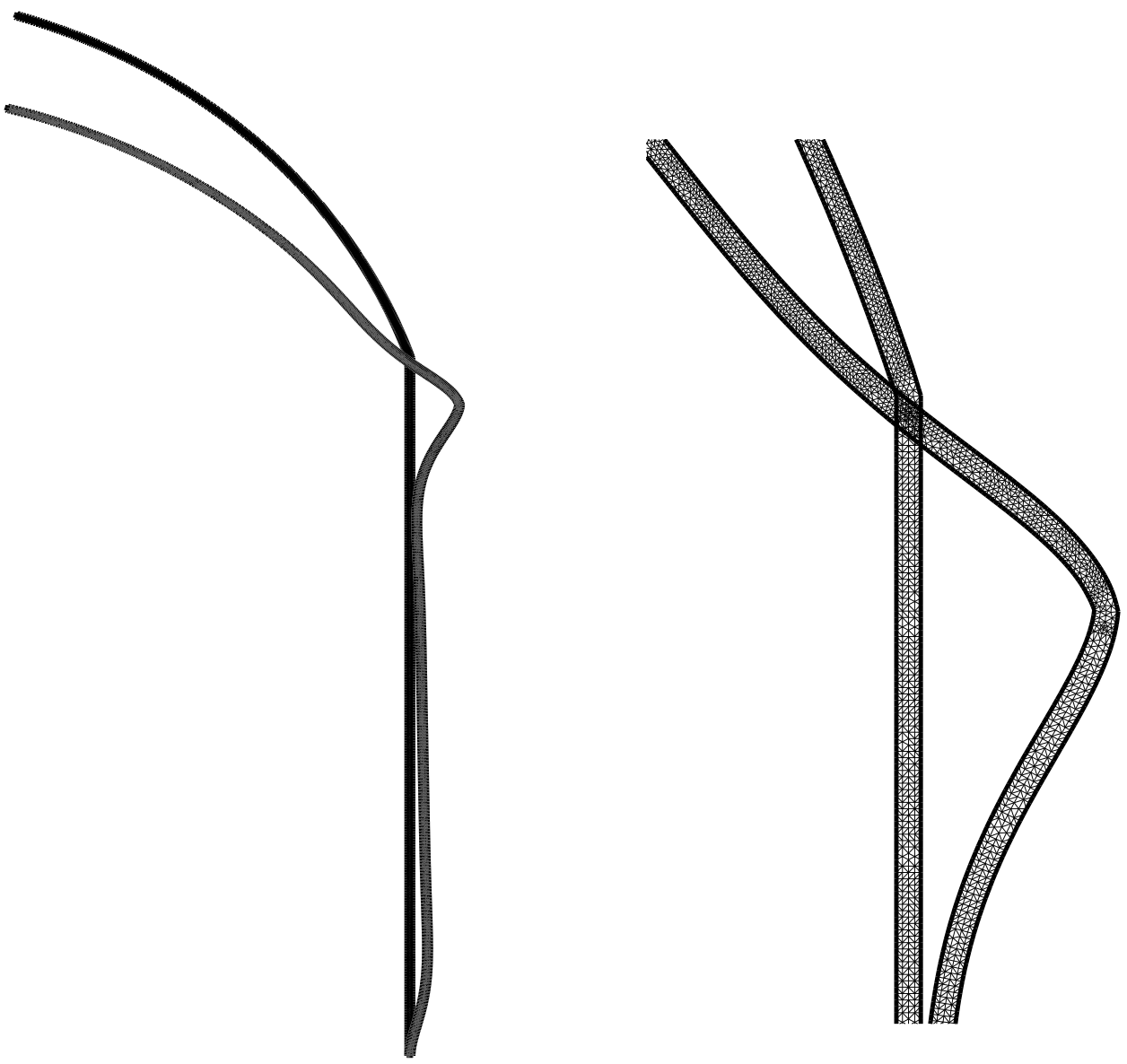

Fig. 5: Reference deformed configuration for rigid junction obtained from a $2 d$ accurate approximation of the axisymetrical problem and zoom of the junction 


\subsection{Rigid junction using Argyris triangle}

For this test, we use the Argyris triangle described in Figure 2 and the mesh given in Figure 6.

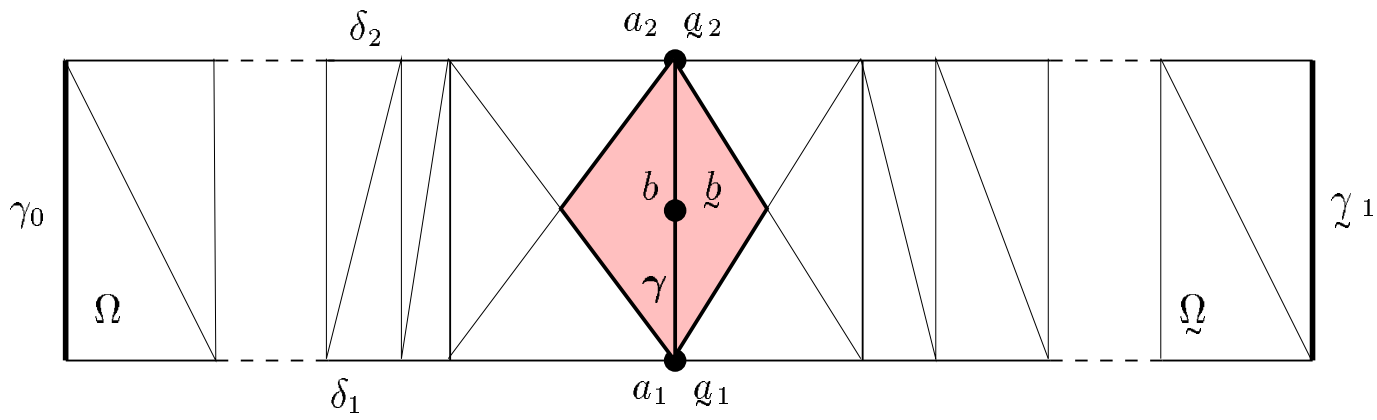

Fig. 6 : Mesh

Because of the axisymmetry of the problem, we restrict the reference domains to an axial strip of width $\ell_{b}=\pi / 16$ and we impose symmetry conditions on the boundaries $\delta_{1}$ and $\delta_{2}$ (Figure 6 ). The rigid junction conditions along $\gamma$ are obtained from equations (3.9) and (3.12). They consist of linear relations between the degrees of freedom located on $\gamma$. The equality of the displacements along the junction is given by $u_{i}=A_{i}^{j} u_{j}$ with $A_{i}^{j}=\boldsymbol{a}_{i} \cdot \boldsymbol{a}^{j}$. In our example, we have :

$A_{1}^{2}=A_{2}^{1}=A_{2}^{3}=A_{3}^{2}=0, A_{1}^{1}=A_{3}^{3}=\cos \delta, A_{2}^{2}=\frac{R}{r} \cos \delta=1, A_{1}^{3}=\sin \delta, \quad A_{3}^{1}=-\sin \delta$

where $\delta$ is defined in Table 1 and Figure 4. Conditions (3.9) can be written as:

$$
\begin{gathered}
\left\{\begin{array}{l}
u_{h 1}\left(a_{\alpha}\right)=\cos \delta u_{h 1}\left(a_{\alpha}\right)+\sin \delta u_{h 3}\left(a_{\alpha}\right) \\
u_{h 2}\left(a_{\alpha}\right)=u_{h 2}\left(a_{\alpha}\right) \\
u_{h 3}\left(a_{\alpha}\right)=-\sin \delta u_{h 1}\left(a_{\alpha}\right)+\cos \delta u_{h 3}\left(a_{\alpha}\right)
\end{array}\right. \\
\left\{\begin{array}{l}
u_{h 1,2}\left(a_{\alpha}\right)=\cos \delta u_{h 1,2}\left(a_{\alpha}\right)+\sin \delta u_{h 3,2}\left(a_{\alpha}\right) \\
u_{h 2,2}\left(a_{\alpha}\right)=u_{h 2,2}\left(a_{\alpha}\right) \\
u_{h 3,2}\left(a_{\alpha}\right)=-\sin \delta u_{h 1,2}\left(a_{\alpha}\right)+\cos \delta u_{h 3,2}\left(a_{\alpha}\right)
\end{array}\right. \\
\left\{\begin{array}{l}
u_{h 1,22}\left(a_{\alpha}\right)=\cos \delta u_{h 1,22}\left(a_{\alpha}\right)+\sin \delta u_{h 3,22}\left(a_{\alpha}\right) \\
u_{h 2,22}\left(a_{\alpha}\right)=u_{h 2,22}\left(a_{\alpha}\right) \\
u_{h 3,22}\left(a_{\alpha}\right)=-\sin \delta u_{h 1,22}\left(a_{\alpha}\right)+\cos \delta u_{h 3,22}\left(a_{\alpha}\right)
\end{array}\right.
\end{gathered}
$$

where $a_{\alpha}, a_{\alpha}$ are displayed on Figure $6, \alpha=1,2$.

The equality of rotations is given by the conditions (see (3.12)):

$$
u_{h 3,1}\left(a_{\alpha}\right)-u_{h 3,1}\left(a_{\alpha}\right)-\frac{1}{R} u_{h 1}\left(a_{\alpha}\right)=0
$$




$$
\begin{gathered}
u_{h 3,12}\left(a_{\alpha}\right)-u_{h 3,12}\left(a_{\alpha}\right)-\frac{1}{R} u_{h 1,2}\left(a_{\alpha}\right)=0 \\
u_{h 3, \nu}(b)-u_{h 3, \nu}(b)-\frac{1}{R} u_{h 1}(b)=0
\end{gathered}
$$

where $b, \quad b$ are the midpoints of $\left[a_{1}, a_{2}\right]$ and $\left[a_{1}, a_{2}\right]$. In the above relation, term $u_{h 1}(b)$ is not a degree of freedom of Argyris triangle, but the expression of the interpolating function for Argyris triangle (see for example Bernadou (1996, (1.5.1), p. 99) give

$$
\begin{aligned}
u_{h 1}(b)= & \frac{1}{2}\left[u_{h 1}\left(a_{1}\right)+u_{h 1}\left(a_{2}\right)\right]+\frac{5}{32}\left[D u_{h 1}\left(a_{1}\right)\left(a_{2}-a_{1}\right)+D u_{h 1}\left(a_{2}\right)\left(a_{1}-a_{2}\right)\right]+ \\
& \frac{1}{64}\left[D^{2} u_{h 1}\left(a_{1}\right)\left(a_{2}-a_{1}\right)^{2}+D^{2} u_{h 1}\left(a_{2}\right)\left(a_{2}-a_{1}\right)^{2}\right] \\
= & \frac{1}{2}\left[u_{h 1}\left(a_{1}\right)+u_{h 1}\left(a_{2}\right)\right]+\frac{5}{32} \ell_{b}\left[u_{h 1,2}\left(a_{1}\right)-u_{h 1,2}\left(a_{2}\right)\right]+\frac{1}{64} \ell_{b}^{2}\left[u_{h 1,22}\left(a_{1}\right)+u_{h 1,22}\left(a_{2}\right)\right]
\end{aligned}
$$

where $\ell_{b}=\pi / 16$ is the width of the radial strip into consideration in this test. The numerical results are given in Figure 7 . They are very closed to the reference solution considered in Paragraph 7.2. This is not surprising since the computation of the reference solution through $2 D$ elasticity equations does not introduce effects of elastic hinge including a jump of rotation. Thus this reference solution is really very closed to the rigid hinge solution. 


$$
011
$$




\subsection{Elastic junction}

In order to simulate an elastic junction, we have implemented in the Modulef code a junction finite element which is built from two Argyris triangles which joint along one of their sides (see Figure 8 ) and whose rigidity matrix includes the bilinear form $b_{h}[.,$.$] . We use again the mesh given in Figure 6$, the junction element is represented in grey. We have seen in Part 1 that the elasticity of the junction depends of a coefficient $k$. When $k$ is small (about 10), the junction is elastic and is very distorded. When $k$ is very large (about $10^{7}$ ), the junction becomes almost rigid and the angle between the two shells remains unchanged during the deformation (see Figure 7).

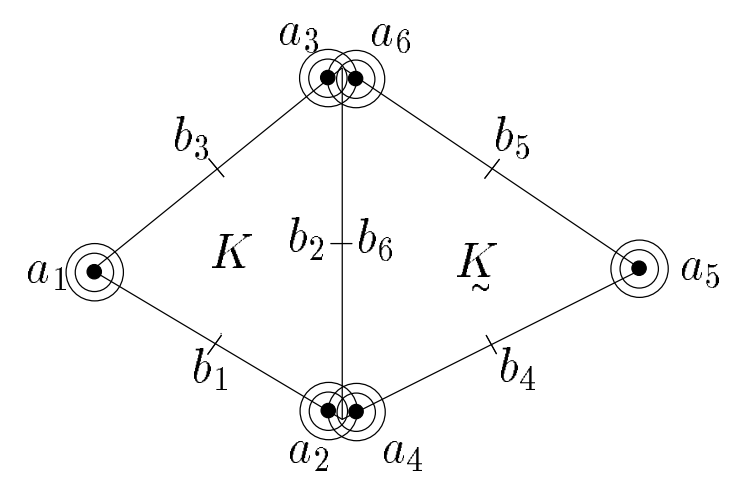

$$
P_{K}=\left(P_{5}\right)^{6} \cap\{\text { relations }(7.1) \text { to }(7.3)\}
$$$$
\operatorname{dim} P_{K}=108
$$

Fig. 8 : Shell junction finite element (interpolation of the unknows $u_{i}$ on $K$ and $u_{i}$ on $\underset{\sim}{K}$ for $i=1,2,3$.)

\section{Final remarks}

In this study we have approximated the thin shell junction problem by using the high accuracy finite element method based on the Argyris element. Another possibility is to use the delinquent finite element introduced by Sander (1985). This element seems promising since it combines high accuracy (an error estimate in $O\left(h^{2}\right)$ in energy norm would seem reasonable) with a choice of degrees of freedom well adapted to the junction problem. These elements are shown schematically in Figure 9. A study along these lines is in progress by Bernadou, Palma, Trouvé and Vilariño (to be published).

Another interesting study would be the study of the junction between two shells modelized by Reissner-Mindlin equations. In this way, the transverse shear effects and the boundary layers phenomena have to be considered. 


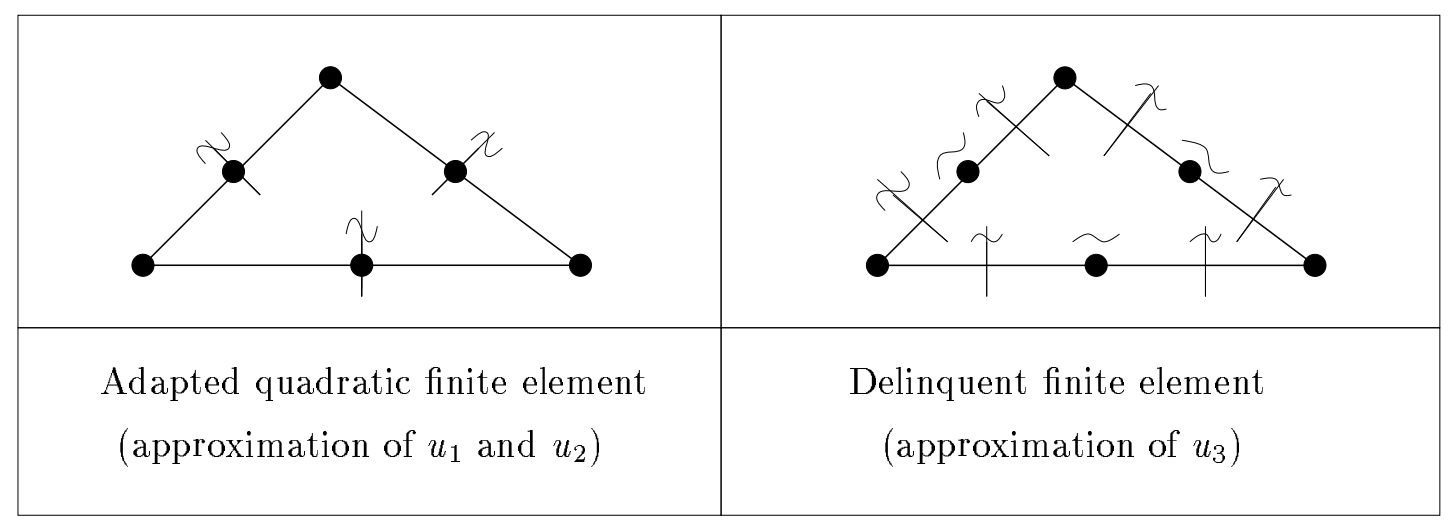

Fig. 9 : An interesting combination of finite elements for the thin shell junction problem

\section{References}

Argyris, J.H., Fried, I., Scharpf, D.W. (1968) : The TUBA family of plate elements for the matrix displacement method, Aero. J. Royal Aeronautical Society, 72, pp. 701-709

Bernadou M. (1996): Finite Element Methods for Thin Shell Problems, J. Wiley \& Sons, Chichester.

Bernadou M., Cubier A. (to appear) Numerical analysis of junctions between thin shells, Part 1 : Continuous problems.

Bernadou M., Fayolle S., Léné F. (1989): Numerical analysis of junctions between plates, Comp. Methods App. Mech. Engrg. 74, pp. 307-326.

Bernadou M., George P.L., Hassim A., Joly P., Laug P., Muller B., Perronet A., Saltel E., Steer D., Vanderbork G., Vidrascu M. (1988): Modulef : Une Bibliothèque Modulaire d'Éléments Finis, I.N.R.I.A

Bernadou M., Palma F., Trouvé P., Vilariño M.A. (to appear)

Ciarlet P.G. (1978) The Finite Element Method for Elliptic Problems, NorthHolland, Amsterdam.

Cubier A. (1994) Analyse et Simulation Numériques de Jonction de Coques Minces, Thèse de l'Université P. et M. Curie.

Dunavant D.A. (1985) High degree efficient symmetrical gaussian quadrature rules for the triangle, Internat. J. Numer. 13, pp. 1129-1148. 
Fayolle S. (1987) Sur l'Analyse Numérique de Raccords de Poutres et de Plaques, Thèse de l'Université P. et M. Curie.

Sander G. (1985) Modèles d'éléments finis délinquants, Groupe de travail "Méthodes Numériques pour les Problèmes de Coques", 17 Janvier 1985, Clamart.

Zenisek A. (1981): Nonhomogeneous boundary conditions and curved triangular finite element, Apl. Mat. 26, pp. 121-140.

Zienkiewicz O.C., Taylor R.L. (1989) The Finite Element Method Fourth Edition Vol. 1, Basic Formulation and Linear Problems, MacGraw-Hill, New York. 


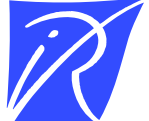

Unit'e de recherche INRIA Lorraine, Technopôle de Nancy-Brabois, Campus scientifique, 615 rue du Jardin Botanique, BP 101, 54600 VILLERS LÈS NANCY

Unit'e de recherche INRIA Rennes, Irisa, Campus universitaire de Beaulieu, 35042 RENNES Cedex

Unit'e de recherche INRIA Rhône-Alpes, 46 avenue F'elix Viallet, 38031 GRENOBLE Cedex 1

Unit'e de recherche INRIA Rocquencourt, Domaine de Voluceau, Rocquencourt, BP 105, 78153 LE CHESNAY Cedex

Unit'e de recherche INRIA Sophia-Antipolis, 2004 route des Lucioles, BP 93, 06902 SOPHIA-ANTIPOLIS Cedex

Éditeur

INRIA, Domaine de Voluceau, Rocquencourt, BP 105, 78153 LE CHESNAY Cedex (France)

ISSN 0249-6399 